WORKING PAPER · NO. 2020-164

\title{
The Economic Consequences of Bankruptcy Reform
}

Tal Gross, Raymond Kluender, Feng Liu, Matthew J. Notowidigdo, and Jialan Wang JULY 2020

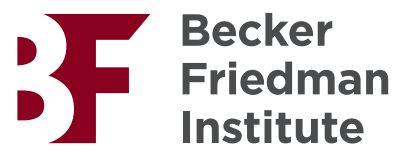




\title{
The Economic Consequences of Bankruptcy Reform*
}

\author{
Tal Gross ${ }^{\dagger} \quad$ Raymond Kluender ${ }^{\ddagger} \quad$ Feng Liu ${ }^{\S}$ \\ Matthew J. Notowidigdo Jialan Wangll
}

July 2020

\begin{abstract}
A more generous consumer bankruptcy system provides greater insurance against financial risks but may also raise the cost of credit. We study this trade-off using the 2005 Bankruptcy Abuse Prevention and Consumer Protection Act (BAPCPA), which increased the costs of filing for bankruptcy. We identify the effects of BAPCPA on borrowing costs using variation in the effects of the reform across credit scores. We find that a one-percentage-point reduction in bankruptcy-filing risk decreased credit-card interest rates by $70-90$ basis points. Conversely, BAPCPA reduced the insurance value of bankruptcy, with uninsured hospitalizations 70 percent less likely to obtain bankruptcy relief after the reform.
\end{abstract}

${ }^{*}$ The views expressed are those of the authors and do not necessarily reflect those of the Consumer Financial Protection Bureau or the United States. We thank Huan Zhao, staff at the California Office of Statewide Health Planning and Development, and Carlos Dobkin for their assistance accessing and compiling datasets used in this project. We are grateful to Amy Finkelstein, Andra Ghent, Paul Goldsmith-Pinkham, Erik Hurst, Richard Hynes, Sasha Indarte, Neale Mahoney, Brian Melzer, Scott Nelson, Christopher Palmer, James Poterba, Amit Seru, Tavneet Suri, Heidi Williams, Jonathan Zinman, four anonymous referees, and seminar participants at MIT, NYU, AEA, Harvard Business School (EM), Arizona, Arizona State, Wharton (BEPP), the Federal Reserve Bank of New York, Microsoft Research, GWU, CFPB, Duke Fuqua (Finance), Harvard Law School, MoFIR, WAPFIN, NBER Summer Institute Corporate Finance and Law and Economics, and SFS Cavalcade sessions for thoughtful feedback and comments. Anran Li, Pinchuan Ong, and Calvin Jahnke provided excellent research assistance.

${ }^{\dagger}$ Boston University and NBER.

${ }^{\ddagger}$ Harvard University.

${ }^{\S}$ Consumer Financial Protection Bureau.

"University of Chicago Booth School of Business and NBER.

"University of Illinois at Urbana-Champaign. 


\section{Introduction}

In recent decades, the rate of consumer bankruptcy filings in the United States climbed from 0.3 percent of households annually in the early 1980s to 1.5 percent in the early 2000 s (Board of Governors, 2006). This five-fold increase in the bankruptcy rate was cited by lawmakers as a reason to pass the 2005 Bankruptcy Abuse Prevention and Consumer Protection Act (BAPCPA). The bill implemented a number of provisions that collectively made filing for bankruptcy more onerous, more expensive, and less financially beneficial.

By making bankruptcy less attractive, BAPCPA was widely expected to reduce bankruptcy filings; however, there was considerable debate regarding how the reform would affect consumer credit markets. Proponents of the bill argued that creditors would pass through higher debtrecovery rates in the form of lower interest rates. Judge Richard Posner argued that "the new Act... should reduce interest rates and thus make borrowers better off" (Posner, 2005). By contrast, critics of the reform argued that a reduction in filings would not be passed-through to borrowers but would instead be captured by lenders. ${ }^{1}$ Additionally, critics contended that claims of abuse were overstated and that the bill would harm filers struggling with medical expenses and job loss (Warren and Tyagi, 2005).

This paper informs this debate by estimating how BAPCPA affected the number of bankruptcy filings, the interest rates offered to consumers in unsecured credit markets, and the likelihood an individual obtains bankruptcy relief in the wake of an adverse health shock. First, we develop a stylized model of consumer bankruptcy to study the relationship between the bankruptcy-filing rate and the cost of credit. We use the model to calibrate a benchmark for the effects of bankruptcy reform on interest rates and find an interest-rate pass-through of $80-113$ basis points for each one-percentage-point change in the bankruptcy-filing rate.

Second, we document that the reform indeed dramatically decreased the number of bankruptcies. We establish this using "excess mass" techniques borrowed from the recent literature studying bunching at tax kinks (e.g., Chetty et al., 2011; Kleven, 2016). We use this approach to estimate the net effect of BAPCPA after accounting for the large increase in bankruptcies just prior to the

\footnotetext{
${ }^{1}$ For instance, Warren (2004) wrote that the "industry never said that the $\$ 44$ billion it planned to recover from bankrupt families would be passed on to customers. History suggests that it would not."
} 
effective date of BAPCPA in October 2005. In the months immediately before the reform, we estimate a net increase in filings of more than 750,000, as consumers rushed to file for bankruptcy before the new bankruptcy code was implemented. Over time, however, we find that the reform reduced the bankruptcy rate by roughly 50 percent. Net of the short-run increase during the "rushto-file period," we estimate that there were roughly one million fewer bankruptcy filings in the two years after BAPCPA than would have occurred without the reform.

One of the central provisions of BAPCPA was a "means test" which restricted the options available to high-income filers and was intended to "ensure that debtors repay creditors the maximum they can afford" (House Report, 2005). The means test was designed to shift filers with higher incomes from Chapter 7 to Chapter 13 by eliminating the option to file under Chapter $7 .{ }^{2}$ Counter to the intent of the law, we find no change in the distribution of income of bankruptcy filers when we proxy for income using the median income in the filer's ZIP Code. ${ }^{3}$ This evidence suggests that the decline in bankruptcies caused by BAPCPA was not concentrated among high-income filers as policymakers had intended. This is consistent with other research which has suggested that the cost of filing for bankruptcy deters filings for many individuals (Gross et al., 2014).

Third, we estimate the pass-through of the change in bankruptcy filings to interest rates by exploiting variation in the effect of the reform on bankruptcy filings across credit scores. To do so, we first estimate the effect of BAPCPA on the bankruptcy-filing rate within each 10-point creditscore segment using credit-report data for a large sample of individuals. We combine the change in filing risk with proprietary data on interest rates of credit-card offers for the same segments. We then estimate event-study and difference-in-difference regression models that compare the change in the average credit-card interest rate to the change in filing risk for each credit-score segment before and after the reform. The key identifying assumption is that interest rates would have evolved similarly across credit-score segments absent the reform. We provide evidence supporting this "common trends" assumption with an event-study figure, which shows no differential trends across

\footnotetext{
${ }^{2}$ Chapter 7 bankruptcy offers filers a "fresh start." All qualifying debts are discharged in exchange for their non-exempt assets. Chapter 13 bankruptcy offers filers a "reorganization." Chapter 13 filers lose no assets, but must commit to a repayment plan out of their future income.

${ }^{3}$ Additionally, we find only a small increase in the share of Chapter 13 filings and find that filings of both chapters declined after the reform. These results suggest that the BAPCPA caused large declines in bankruptcy rates across a broad range of consumers, swamping an effect of the means test on inducing consumers to switch between Chapter 7 and Chapter 13.
} 
credit-score segments in the years leading up to the reform. We also show that the main results are robust to subprime-by-year-month fixed effects, suggesting that the results are not driven by other unobserved factors differentially affecting the subprime credit market during this time period.

\section{We find that a one-percentage-point decline in bankruptcy-filing risk within a credit-score seg-} ment decreases average interest rates by 70-90 basis points. Interpreting these estimates through the lens of the model-based calibration, we conclude that a meaningful share of the cost savings to creditors was passed on to consumers in the form of lower interest rates. Additionally, according to the model, the pass-through results imply that lenders expected that the marginal non-filers i.e., the consumers deterred from filing by BAPCPA — would ultimately repay a meaningful share of their unsecured debts. We use detailed loan-level data to provide corroborating evidence that the interest-rate response we estimate is associated with real changes in loan performance.

\section{Our last contribution is documenting that BAPCPA reduced the bankruptcy-filing rate following} a hospital admission. Building on the event-study approach of Dobkin et al. (2018a) that uses variation in the timing of hospitalizations, we find that an uninsured hospitalization increases the likelihood of filing for bankruptcy by 1.5 percentage points prior to the reform, but by just 0.4 percentage points after the reform. The reduction in the likelihood that an uninsured hospitalization obtains bankruptcy relief occurs right around the implementation of BAPCPA, and the reduction is persistent. While a hospitalization is just one example of an adverse shock, to the extent that this finding generalizes to other types of adverse shocks, these results provide suggestive evidence that the bankruptcies deterred by BAPCPA were not limited to the most "abusive" filings. Instead, these results imply that BAPCPA may have meaningfully reduced the insurance value of bankruptcy. ${ }^{4}$

Taken together, the results in this paper suggest that BAPCPA reduced bankruptcy filings, but not in the targeted way that proponents had intended. Nevertheless, the law still appears to have provided some benefit to consumers in the form of lower credit-card interest rates, and the model clarifies that the pass-through we estimate is consistent with relatively high "all-in" costs of filing (accounting for the filing fees, legal costs, and stigma costs associated with filing). Our results highlight the stark trade-off for policymakers: marginal non-filers may benefit substantially from a

\footnotetext{
${ }^{4}$ While the share of bankruptcies caused by hospitalizations appears to be small according to Dobkin et al. (2018b), it is a frequently-cited source of financial risk faced by households and one the bankruptcy system is frequently referenced as insuring.
} 
more generous bankruptcy system (getting a "fresh start" instead of repaying a meaningful share of their debts), but these benefits come at the cost of higher interest rates for other consumers.

This paper contributes to three main areas of research. First, it contributes new, reducedform empirical evidence on the effects of BAPCPA. Several previous studies have explored the impacts of BAPCPA using reduced-form methods. Albanesi and Nosal (2018) study the likelihood that consumers delinquent on their debts transition to declaring bankruptcy and estimate transition probabilities before and after BAPCPA. They find that transition probabilities into Chapter 7 bankruptcy decreased after BAPCPA, while transition probabilities into insolvency increased. Chakrabarti and Pattison (2019) focus on BAPCPA's effect on auto loans, in particular the reform's elimination of "cramdowns" in Chapter $13 .{ }^{5}$ The authors compare the impact of BAPCPA in states with a high share of Chapter 13 bankruptcies to states in which Chapter 13 was historically rare and find the elimination of auto loan cramdowns under Chapter 13 reduced interest rates on auto loans. There exist relatively few other reduced-form studies of BAPCPA's effect on creditmarket outcomes. Li et al. (2011) examine mortgages and find that, by worsening the bankruptcy option for homeowners, BAPCPA increased foreclosure rates. ${ }^{6}$

Relative to these previous studies, this paper estimates the causal impact of the reform on interest rates for unsecured loans, the most commonly held type of debt and the most frequently discharged in bankruptcy. We are not aware of other work that uses variation in the effect of BAPCPA on bankruptcy filings across credit scores for identification. We develop this empirical approach, assess its validity, and present the first quasi-experimental estimates of the effect of BAPCPA on credit-card interest rates. ${ }^{7}$ This paper also estimates changes in the rate at which uninsured hospitalizations lead to bankruptcy around the time of BAPCPA, which speaks to the "insurance value" of bankruptcy. Both of these estimates are key inputs into a more comprehensive evaluation of bankruptcy reform and speak to the trade-off of lower interest rates versus more generous social insurance.

Second, this paper is related to studies of the consumer bankruptcy system that calibrate

\footnotetext{
${ }^{5}$ Cramdowns in Chapter 13 allowed borrowers to reduce the principal of their loan to the current market value of the vehicle.

${ }^{6}$ Mitman (2016) and Morgan et al. (2012) also conclude that the reform increased foreclosure rates.

${ }^{7}$ Severino and Brown (2017) study the effect of bankruptcy on interest rates for unsecured credit but focus on the pre-BAPCPA era, studying changes in state homestead exemptions.
} 
structural models (Zame, 1993; Dubey et al., 2005; Livshits et al., 2007; Chatterjee et al., 2007; Mitman, 2016; Nakajima, 2017). Those models emphasize the trade-off between using bankruptcy to smooth consumption across states of the world and the higher cost of smoothing consumption over time, often while assuming perfectly competitive credit markets (and thus full pass-through of the costs of lending to consumers). Our estimates of interest-rate pass-through provide some empirical support to the assumptions underlying these models of bankruptcy and credit markets.

Finally, this paper provides new evidence on pass-through in consumer credit markets. Existing research on pass-through in credit markets emphasizes sticky interest rates (and thus limited passthrough), but this research typically estimates pass-through using shocks to the cost of funds rather than shocks to default risk (e.g., Ausubel, 1991; Calem and Mester, 1995; Stavins, 1996; Stango, 2000; Calem et al., 2006; Agarwal et al., 2017). We thus contribute new evidence to this literature by estimating how changes in bankruptcy-filing risk are passed-through to credit-card interest rates. While a full reconciliation of the different pass-through estimates is beyond the scope of this paper, Grodzicki (2017) argues that credit-card markets have become more competitive in recent years following the costly adoption of screening technology, which is consistent with the price responsiveness to changes in default risk that we document in this paper. ${ }^{8}$

The remainder of this paper proceeds as follows. The next section provides background information on bankruptcy before and after BAPCPA. Section 3 develops a simple model that we use to calibrate a reasonable benchmark for the effects of bankruptcy reform on interest rates. Section 4 describes our data sources and sample construction. Section 5 evaluates how BAPCPA affected the number of bankruptcy filings. Section 6 then estimates the pass-through of this decline in bankruptcy to borrowing costs. Section 7 estimates the effect of BAPCPA on the bankruptcy-filing rate following a hospital admission. Section 8 concludes.

\footnotetext{
${ }^{8}$ More broadly, this paper is also related to other empirical studies of pass-through in imperfectly competitive markets, such as recent work on Medicare Advantage (Cabral et al., 2018) and the Spanish electricity market (Fabra and Reguant, 2014).
} 


\section{Institutional Background}

In contrast to other developed countries, American consumers have historically enjoyed an exceptionally debtor-friendly bankruptcy system. ${ }^{9}$ In particular, American consumers filing for bankruptcy have had the option to freely choose between a "fresh start" (liquidating outstanding debts through Chapter 7) and a "reorganization" of debts (repaying debts on an installment plan over several years through Chapter 13). Chapter 7 filers must forfeit all non-exempt assets in exchange for discharge of their debt, while Chapter 13 filers are allowed to keep all of their assets but must repay their debt out of future income.

Despite the potential financial benefits for many consumers, consumer bankruptcy has historically been a relatively rare phenomenon in the United States. In the late 1970s, just 0.3 percent of households filed for bankruptcy in a given year. In 1978, the United States adopted a new bankruptcy code and legalized advertisements by bankruptcy attorneys. A 1978 Supreme Court decision allowed banks to export their home interest rates and effectively evade state usury laws. ${ }^{10}$ These changes in policy catalyzed the growth of unsecured borrowing in the ensuing decades (White, 2007). By 1999, the bankruptcy rate had increased to 1.5 percent annually, prompting creditors to lobby for a more stringent bankruptcy code.

To make their case, credit-industry lobbyists pointed to a handful of high-profile cases of "exemption shopping." For those bankruptcies, debtors moved across state lines to select the most beneficial bankruptcy regime, and this was held up as emblematic of the abuse rampant in the bankruptcy system. A reform of the bankruptcy system was first drafted in 1998 and passed by Congress in 2000, but pocket-vetoed by President Clinton. The bill was reintroduced each Congress until it finally passed with broad bipartisan support in 2005. The Senate passed the bill on March 10, 2005, the House on April 14, 2005, and the bill was signed by President Bush on April 20, 2005. The new bankruptcy code went into effect for all bankruptcies filed on or after Monday, October 17, 2005.

\footnotetext{
${ }^{9}$ Italy, for instance, had no form of consumer bankruptcy until 2015, and Germany only began allowing consumer bankruptcy in 1999. Before then, consumers in those countries had few options to discharge their debts (Tabb, 2005).

${ }^{10}$ In Marquette National Bank of Minneapolis v. First of Omaha Service Corporation (439 U.S. 299 (1978)), the U.S. Supreme Court ruled that state anti-usury laws regulating interest rates are not enforceable against nationally chartered banks based in other states.
} 
BAPCPA made filing for bankruptcy less attractive in three primary ways. First, the law sought to prohibit higher-income households from filing Chapter 7. To do so, lawmakers introduced a means test which they referred to as "the heart of the bill" (House Report, 2005). The means test added a "presumption of abuse" for filers whose income is above certain thresholds. Debtors are subject to the means test if their income from the previous six full months before filing, adjusted for family size, is more than the state median income (Parra, 2018). ${ }^{11}$ Debtors subject to the means test are functionally prohibited from filing Chapter 7, and can only file Chapter 13 (which, post-BAPCPA, required higher repayment). This created an incentive for borrowers to suppress their labor supply and earnings below the state median in order to skirt the means test and file Chapter 7 or reduce their repayment obligation under Chapter $13 .^{12}$

Second, BAPCPA limited the benefits of filing for bankruptcy along a number of dimensions. Prior to BAPCPA, Chapter 13 filers could propose their own repayment plan and faced no incentive to offer a repayment plan more generous than the relief they would receive under Chapter 7. After BAPCPA, Chapter 13 filers are required to forfeit 100 percent of their disposable income for five years to pay down their debts. ${ }^{13}$ The reform also limited the ability of filers to discharge some purchases and "exemption shop" for the most favorable state bankruptcy regime. Debtors who move must now wait two years before they are allowed to file under their new state's exemptions. Bankruptcy filers must wait a set number of years before they are allowed to file again. BAPCPA increased the waiting period from six years to eight years for Chapter 7 and from six months to two years for Chapter 13 .

Finally, BAPCPA made the process of filing for bankruptcy much more burdensome and expensive. Bankruptcy court fees increased, and bankruptcy filers are now required to take two educational courses: a credit-counseling course before filing and a financial-management course

\footnotetext{
${ }^{11}$ Virtually all income is included in this calculation with the notable exception of Social Security income. Those with debts that are not "primarily consumer debts" (e.g. business investments) are also exempt from the means test. Debtors with monthly disposable income of less than $\$ 100.00$ were exempt and this cutoff increased to $\$ 166.67$ depending on the share of unsecured debt this represents. Beginning in 2007, these numbers increased to $\$ 109.58$ and $\$ 182.50$.

${ }^{12}$ The incentive to suppress income prior to filing is relevant even if households cannot suppress it enough to get under the state median. Chapter 13 repayment plans, which are paid over the subsequent five years, are based on documented disposable income over the prior six months. As White (2007) points out, a reduction in monthly earnings of $\$ 1$ for the six months prior to filing costs filers $\$ 6$ in the short run but reduces their repayment requirement by $\$ 60$ ( $\$ 1$ each month over the next 60 months).

${ }^{13}$ Allowances for living expenses vary by metropolitan area and are largely based on the Internal Revenue Service policies for the treatment of delinquent taxpayers.
} 
before their debt is discharged. Filing requirements increased and bankruptcy attorneys were made liable for any inaccuracies in the filing, which increased attorney costs by as much as $\$ 500$ and subsequently increased the fees they charged their clients (House Report, 2005). ${ }^{14}$ Altogether, these changes increased the average financial cost of filing from $\$ 868$ to $\$ 1,309$ for Chapter 7 and from $\$ 2,260$ to $\$ 2,861$ for Chapter 13 (Lupica, 2012).

\section{Economic Framework}

In this section, we discuss a simple model of consumer bankruptcy and use it to study changes in bankruptcy filings and borrowing costs. ${ }^{15}$ We use the model to calibrate a reasonable benchmark for the effects of bankruptcy reform on interest rates. Appendix Section A provides additional formulas and the full derivations behind the claims in this section.

\subsection{Model Setup}

There are $I$ different types of individuals, indexed by $i \in\{1, \ldots, I\}$. The types are intended to correspond to the credit-score "segments" that we use in our empirical analysis. There is a unit mass of each type, and individuals within each type are ex-ante identical and live for two periods. In the first period, each individual borrows $b_{i}$ at interest rate $r_{i}$, so if the debt is repaid in full in the second period, then $\left(1+r_{i}\right) b_{i}$ is repaid. ${ }^{16}$

In the second period, each individual receives income $y$, drawn from the distribution $f_{i}(y)$, which has the associated CDF $F_{i}(y)$. After drawing their income, individuals can either repay their outstanding debt, or they can file for bankruptcy and retain all of their assets up to an exemption level, $e$. When individuals file, they must also pay cost $c$, which captures all of the relevant fixed costs of filing: filing fees, legal costs, hassle costs, and stigma.

This setup leads to a simple decision rule: an individual will file for bankruptcy if income (net of full repayment of debt) is less than the exemption amount minus the cost of filing $(e-c)$; that

\footnotetext{
${ }^{14}$ There is some dispute over whether Chapter 7 legal fees are dischargeable in bankruptcy, but they are nearly always collected by the attorney before the filing (Herring, 2018).

${ }^{15}$ The model we develop is most closely related to the model of Wang and White (2000), who simulate various bankruptcy reforms, but do not discuss the determinants of the magnitude of pass-through.

${ }^{16}$ We treat $b_{i}$ as exogenous throughout this simple framework. In reality, changes in the bankruptcy code should also affect the amount borrowed, but we make this simplification given the relatively short-run nature of our empirical analysis.
} 
is, if $y-\left(1+r_{i}\right) b_{i}<e-c$. When individuals file for bankruptcy, creditors recover $\max \{0, y-e\} .{ }^{17}$

\subsection{Impact of Bankruptcy Reform on the Cost of Credit}

Within the population of borrowers of each type, the probability of filing for bankruptcy is $p_{i}=$ $F_{i}\left(e+\left(1+r_{i}\right) b_{i}-c\right)=F_{i}\left(y_{i}^{*}\right)$, where $y_{i}^{*}$ is the second-period income at which a borrower of type $i$ is indifferent between filing and not filing. The decision rule implies that increases in the exemption level and the cost of filing have equal and opposite effects on filing, with the magnitude determined by the mass of marginal individuals indifferent to filing prior to the reform; i.e., $\partial p_{i} / \partial e=f_{i}\left(y^{*}\right)>0$ and $\partial p_{i} / \partial c=-f_{i}\left(y^{*}\right)<0$.

To determine the effects of $e$ and $c$ on borrowing costs, we assume that the credit market is perfectly competitive, so that the amount borrowed is equal to the expected amount recovered by lenders. Using the zero-profit condition that implicitly determines $r_{i}$, we derive the following expression for $d r_{i} / d p_{i}$, which is the pass-through to interest rates of a reform-induced change in bankruptcy filings:

$$
\frac{d r_{i}}{d p_{i}}=\frac{c / b_{i}}{1-p_{i}}=\frac{1+r_{i}}{1-p_{i}} \cdot \frac{c}{\left(1+r_{i}\right) b_{i}}>0
$$

This expression shows that a bankruptcy reform that decreases bankruptcies (either by reducing exemptions or raising filing costs) decreases the interest rate, with the magnitude of the decrease scaled by $c / b_{i}{ }^{18}$ Since $c$ represents the amount repaid to creditors by the marginal non-filers, for bankruptcy reform to have a meaningful effect on interest rates, it must be the case that marginal non-filers repay a meaningful share of their debts. Intuitively, meaningful pass-through of bankruptcy reform into interest rates requires that marginal non-filers must face substantial (financial, hassle, and stigma) costs of filing. ${ }^{19}$

To calibrate a reasonable pass-through benchmark, we re-arrange equation (1) into a product of two terms: the first term is the ratio $\frac{1+r_{i}}{1-p_{i}}$, and the second term, $\frac{c}{\left(1+r_{i}\right) b_{i}}$, represents what creditors

\footnotetext{
${ }^{17}$ Consistent with the fact that the costs of filing are typically paid in advance, in the model $c$ must be paid out exempt assets. Additionally, we assume that $f_{i}(y)$ has no support below $c$ for all types, and in the Appendix Section A.3 we work through the case where individuals with income below $c$ are insolvent and unable to file for bankruptcy.

${ }^{18}$ The full derivation of this expression is given in the Online Appendix, including the technical conditions needed for the expression to be independent of whether the reform changes $e$ or $c$.

${ }^{19}$ There is existing evidence that the collective cost of filing for bankruptcy is high. White (1998), for instance, estimated that 15 percent of households could benefit from filing for bankruptcy at a time when just over one percent did, and Indarte (2018) finds evidence of relatively large "all-in" costs of filing for bankruptcy.
} 
recover from the marginal non-filer, $c$, divided by the expected repayment of non-filers, $\left(1+r_{i}\right) b_{i}$. In other words, this second term represents the counterfactual recovery rate for the borrowers who are deterred (at the margin) from filing for bankruptcy.

We calibrate the first term using measures of $r_{i}$ and $p_{i}$ for each credit-score segment using the Consumer Financial Protection Bureau Consumer Credit Panel (CCP) and Mintel Comperemedia (Mintel) data on credit-card offers. To capture a more accurate measure of borrowing costs, we scale up the credit-card interest rates based on the Nelson (2018) estimates of the difference between interest charges and fee-inclusive borrowing costs for the most closely corresponding credit-score segment. ${ }^{20}$

To calibrate the second term in equation (1), we calculate default rates for each credit-score segment using the CCP. Specifically, we calculate the probability that a newly opened credit-card loan becomes 30-, 60-, 90-day past due or in default within 12 months after opening. To use the average default rates in our calibrations, we make two key assumptions. First, we assume that the default rate can be used as a proxy for one minus the recovery rate. This will be a reasonable assumption if the expected recovery rate is small conditional on default, and the recovery rate is high if individuals do not enter default. ${ }^{21}$ Second, we assume that the average default rate within a credit-score segment is informative about the recovery rate for the marginal individual deterred from bankruptcy by the reform. This may be a reasonable assumption in our setting because we use relatively fine 10-point credit-score segments in our main analysis, and credit scores at origination are designed to be the best single predictor of borrowing costs and default.

Table 1 presents the calibration results for different groups of credit-score segments (e.g., prime, subprime) and using different default rates as proxies (30-, 60-, 90-days delinquent and in-default). The table shows a range of pass-through values, suggesting that a one-percentage-point reduction in bankruptcy-filing rate reduces interest rates by between 80 and 113 basis points. ${ }^{22}$

We take the range of pass-through values in Table 1 to be a reasonable benchmark for the

\footnotetext{
${ }^{20}$ Specifically, we estimate the mark-up due to fees by calculating the ratio between the fee inclusive charges and interest charges from Table 6 (Pre-CARD Act Price Distribution on New Accounts) in Nelson (2018). We use the credit-score-segment mark-ups from accounts with 6-11 months of cumulative borrowing. The mark-ups are similar to those implied by the survey respondents in Stango and Zinman (2009).

${ }^{21}$ Appendix Table A1 presents the probability of each out successive outcome for each credit-score segment.

${ }^{22}$ Appendix Table A1 presents the calibration results for each 10-point credit-score segment and default rate.
} 
empirical analysis, but the true pass-through value could deviate from the calibration results for several reasons. First, some individuals deterred from bankruptcy are likely to remain persistently insolvent and enter "informal bankruptcy" (Dawsey and Ausubel, 2002). If the share entering "informal bankruptcy" among marginal non-filers is larger than the overall share in the credit-score segment, then the calibration results will overstate the actual change in interest rates. Conversely, marginal non-filers could repay their debts at higher-than-average rates if the high hassle costs or stigma costs of filing deter the borrowers who are most likely to repay their debts (Indarte, 2018). Second, the calibration exercise assumes perfect competition, but if the credit market is imperfectly competitive, then this could either reduce or increase pass-through relative to the perfectly competitive benchmark (Herkenhoff and Raveendranathan, 2020; Mahoney and Weyl, 2017). Finally, with an endogenous borrowing decision, lower interest rates could increase dynamic reborrowing and change the selection of borrowers, both of which could affect pass-through (Nelson, 2018).

Table 1. Benchmarking Interest Rate Pass-through

\begin{tabular}{|c|c|c|c|c|c|c|c|c|}
\hline (1) & $(2)$ & $(3)$ & $(4)$ & (5) & (6) & (6) & $(7)$ & (8) \\
\hline \multirow{2}{*}{$\begin{array}{c}\text { Credit } \\
\text { Score } \\
\text { Segment }\end{array}$} & \multirow[b]{2}{*}{$\begin{array}{l}\text { Population } \\
\text { Share }\end{array}$} & \multirow[b]{2}{*}{$\begin{array}{c}\text { Bankruptcy } \\
\text { Rate }\end{array}$} & \multirow[b]{2}{*}{ APR } & \multirow[b]{2}{*}{$\begin{array}{c}\text { APR } \\
+ \text { Fees }\end{array}$} & \multirow[b]{2}{*}{$\begin{array}{l}\text { Default } \\
\text { Measure }\end{array}$} & \multirow{2}{*}{$\begin{array}{l}\text { Share of } \\
\text { Loans } \\
\text { Past Due }\end{array}$} & \multicolumn{2}{|c|}{ Pass-through Calibration } \\
\hline & & & & & & & $\overline{\mathrm{APR}}$ & $\begin{array}{c}\text { APR } \\
+ \text { Fees }\end{array}$ \\
\hline \multirow[t]{4}{*}{ Subprime } & $26.2 \%$ & $3.1 \%$ & $13.4 \%$ & $23.1 \%$ & 30+ Days & $31.6 \%$ & 0.80 & 0.87 \\
\hline & & & & & $60+$ Days & $28.5 \%$ & 0.84 & 0.90 \\
\hline & & & & & $90+$ Days & $26.4 \%$ & 0.86 & 0.93 \\
\hline & & & & & Default & $20.7 \%$ & 0.93 & 1.00 \\
\hline \multirow[t]{4}{*}{ Prime } & $73.8 \%$ & $0.3 \%$ & $10.2 \%$ & $12.8 \%$ & $30+$ Days & $0.8 \%$ & 1.10 & 1.12 \\
\hline & & & & & $60+$ Days & $0.5 \%$ & 1.10 & 1.13 \\
\hline & & & & & $90+$ Days & $0.4 \%$ & 1.10 & 1.13 \\
\hline & & & & & Default & $0.2 \%$ & 1.10 & 1.13 \\
\hline \multirow[t]{4}{*}{ All } & $100.0 \%$ & $1.0 \%$ & $11.0 \%$ & $15.5 \%$ & 30+ Days & $8.9 \%$ & 1.02 & 1.05 \\
\hline & & & & & $60+$ Days & $7.8 \%$ & 1.03 & 1.07 \\
\hline & & & & & $90+$ Days & $7.2 \%$ & 1.04 & 1.08 \\
\hline & & & & & Default & $5.6 \%$ & 1.06 & 1.10 \\
\hline
\end{tabular}

Notes: This table reports pass-through estimates split by prime and subprime consumers and using different default measures to proxy for the repayment rates of marginal non-filers. See Appendix Table A1 for the full analysis by 10-point credit-score segment. Subprime includes all individuals with credit scores less than or equal to 620. The APR column comes from Mintel data on credit card offers, scaled up to include fees as specified in the main text. The bankruptcy rate and default rates (both measured over the next 12 months) come from the Consumer Credit Panel (CCP). 12-month default rates represent loans originated between January 2003 and June 2004. The pass-through estimate comes from combining the estimates in columns according to equation (1), using the default rate to proxy for one minus the recovery rate, which is the $c /\left(\left(1+r_{i}\right) b_{i}\right)$ term in equation (1). 


\section{Data}

Our analysis relies on four main data sets: legal dockets for all consumer bankruptcies in 78 (of 94) United States bankruptcy courts; Mintel Comperemedia data on credit-card offers made to more than 2,000 consumers each month; the Consumer Financial Protection Bureau Consumer Credit Panel 1-in-48 sample of consumer credit reports; and, hospital-discharge records for over half a million individuals merged with a ten-year panel of their credit reports.

Data on consumer bankruptcy filings come from the Public Access to Court Electronic Records (PACER) system. This dataset includes more than three million filings from 78 bankruptcy courts during our sample period of 2004 through 2007, roughly 86 percent of all filings in the United States during that period. Throughout our analysis, we limit the sample to 2007 and earlier in order to mitigate the potentially confounding effects of the Great Recession on our results. We validate the data for each district by comparing the filings in the PACER records with the official totals published by the Administrative Office of the United States Courts (AOUSC). ${ }^{23}$ Appendix Table A2 details the sample coverage by chapter and quarter-year, and Appendix Section B.1 provides more details on the sample.

To study pass-through to credit-market prices, we use Mintel Comperemedia (Mintel) data on credit-card offers. Mintel collects credit-card offers from a representative sample of households in the United States, who are paid to send all direct-mail credit-card offers they receive to Mintel. ${ }^{24}$ The data includes demographic information on the households (age of head of household, household composition), details on the credit-card offers (type of credit, interest rates, fees), and some limited credit measures (importantly, these include the same credit score observed in the Consumer Financial Protection Bureau Consumer Credit Panel (CCP)). Data is collected monthly and includes approximately 350,000 credit-card offers (7,000 per month) and 100,000 individual-month observations (2,200 per month). Appendix Table A3 provides summary statistics on offers, and Appendix Section B.3.1 provides more details on data construction. We do not observe bankruptcy filings

\footnotetext{
${ }^{23}$ The sample does not include the universe of bankruptcies because 13 districts did not grant fee waivers, and we drop 3 districts from the sample because the bankruptcies in the data do not match the AOUSC statistics.

${ }^{24}$ The Mintel sample is representative of all direct-mail credit-card offers. Comparing the households surveyed by Mintel with the 2007, 2010, and 2013 waves of the Survey of Consumer Finances, Han et al. (2018) find that, in addition, it is broadly representative of the U.S. population.
} 
in the Mintel data, so we use the CCP to estimate the bankruptcy-filing risk for each credit-score segment, combining public-record snapshots with credit-score archives to estimate prospective filing probabilities. We also use the CCP data to examine the delinquency and default rates for new credit-card tradelines by the month and credit score at origination. Appendix Section B.2 provides more details on our processing of the CCP data.

To study changes in the insurance value of bankruptcy, we analyze administrative hospitaldischarge records from the California Office of Statewide Health Planning and Development for the universe of uninsured hospitalizations (and approximately 20 percent of individuals hospitalized with insurance) between 2003 and 2007. Our sample links hospitalized individuals to their panel of credit reports spanning the years 2002 to 2011. To isolate hospitalizations that are likely to be unexpected, we restrict the sample to individuals aged 25 to 64 who are hospitalized for nonpregnancy-related reasons and have not previously been to the hospital in the last three years. Appendix Table A4 provides pre-hospitalization summary statistics and Appendix Section B.4 provides more details on the sample.

\section{$5 \quad$ Effects of BAPCPA on Bankruptcy Filings}

A first prediction of the model discussed in Section 3 is that higher costs of bankruptcy lead to fewer bankruptcies. This section tests that prediction empirically by studying the effect of BAPCPA on total filings. Next, we test whether BAPCPA changed the composition of bankruptcy filers in ways that policymakers had intended.

\subsection{Total Filings}

Figure 1 plots the total number of consumer bankruptcy filings in the PACER sample by week from January 2004 through December 2007. The most striking feature of Figure 1 is the dramatic rush to file after BAPCPA was signed but before the bankruptcy code was changed. In the five weeks before the law was implemented, from September $12^{\text {th }}$ through October $16^{\text {th }}$, the filing rate increased dramatically. In the final week before the implementation of the law, more than 400,000 households declared bankruptcy, roughly 13 times the typical weekly caseload.

To quantify the number of excess filings before implementation and to test whether, on net, 
Figure 1. Time-Series of Bankruptcy Filings

Weekly consumer bankruptcy filings

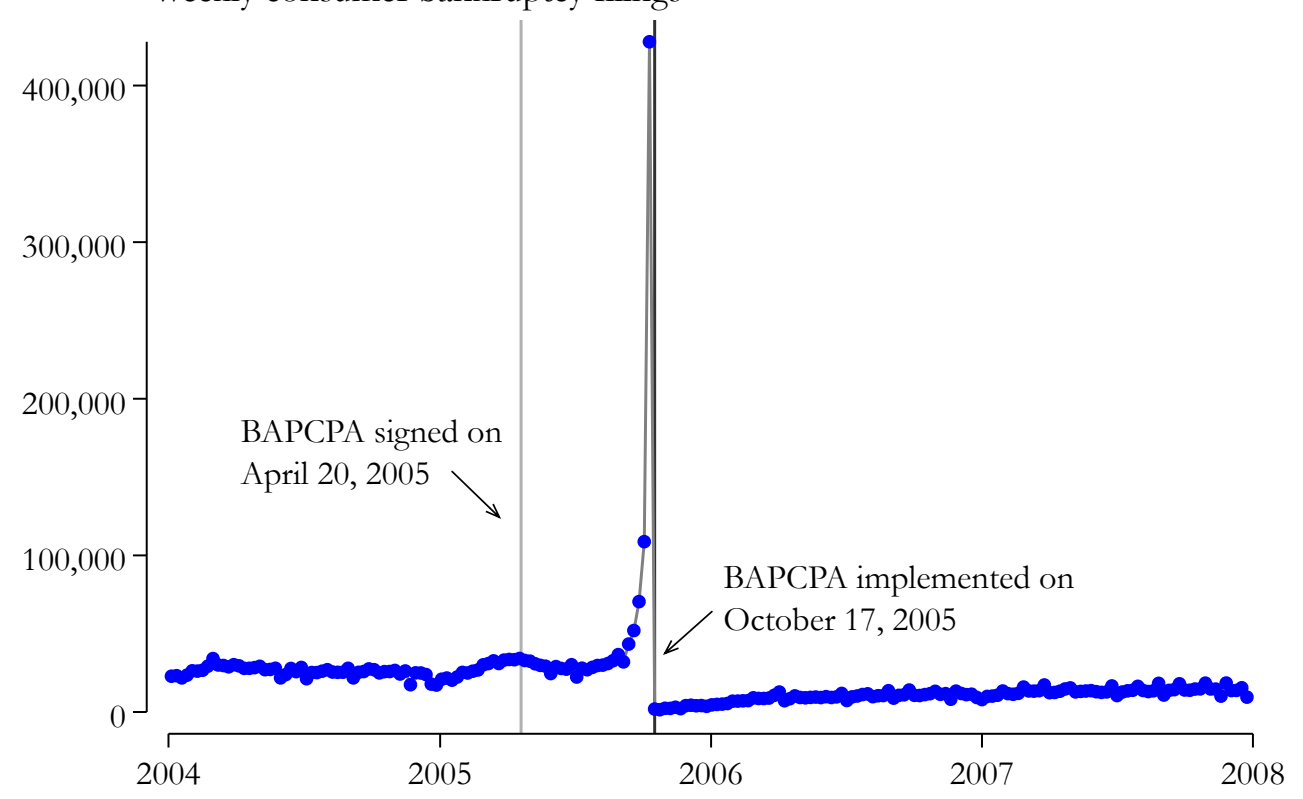

Notes: The sample consists of all consumer bankruptcy filings included in the PACER sample from January 2004 through December 2007. Each dot in the figure represents the total number of filings for that week.

the law led to a reduction in bankruptcies, we adapt "excess mass" methods from the tax-notch literature (e.g., Chetty et al., 2011; Kleven, 2016) to generate a counterfactual time-series in the absence of the changes to the bankruptcy code. We fit the following regression to the weekly filing count in the period before BAPCPA was passed by the Senate (March 10, 2005):

$$
\text { Filings }_{t}=\gamma t+\tau_{m}+\varepsilon_{t}
$$

Here, Filings ${ }_{t}$ are nationwide filings in week $t, t$ is a linear time trend, and $\tau_{m}$ are calendar-month fixed effects.

We use equation (2) to predict the counterfactual number of filings each week for the full sample period and calculate the sum of the difference between the predicted and actual filings for each week. Figure 2 presents this exercise by plotting the time-series of bankruptcy filings against the estimated counterfactual. ${ }^{25}$ As expected, the predicted filings closely match actual filings before the passage of the law. Actual filings diverge from the predicted time-series in September of 2005 in advance

\footnotetext{
${ }^{25}$ Appendix Figure A2 extends the pre-period back to 2002 and shows similar results.
} 
Figure 2. Excess and Missing Mass of Bankruptcy Filings

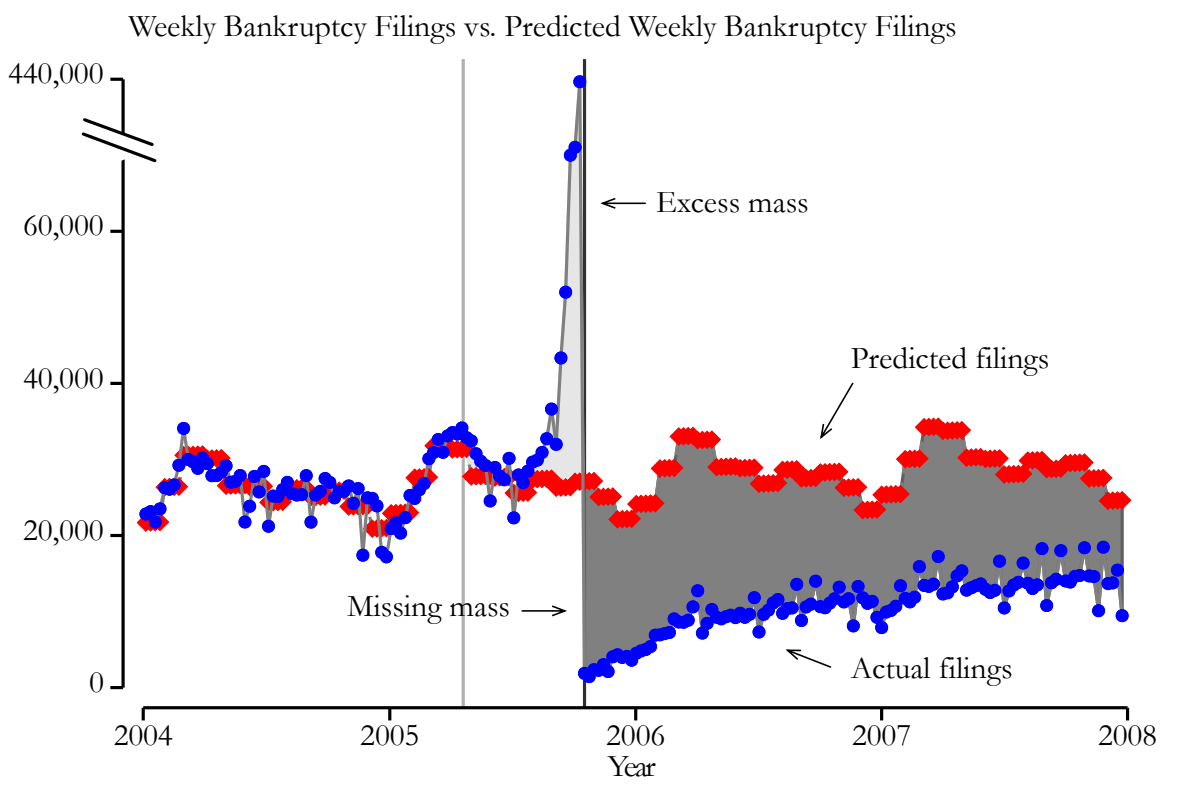

\begin{abstract}
Notes: The sample consists of all consumer bankruptcy filings included in the PACER sample from January 2004 through December 2007. The total count of filings for each week is plotted against the predicted number of filings for the week. The predicted number of filings are the result of estimating equation (2) on the total count of filings from January 2004 through the day that BAPCPA was passed by the Senate (March 10, 2005). The three data points before the implementation of BAPCPA are the three largest values in the time series: there were 70,457 filings during the week that began on September 26, 2005; 108,745 filings during the week that began on October 3, 2005; and 427,947 filings during the week that began on October 10, 2005.
\end{abstract}

of the pre-BAPCPA filing deadline in mid-October. An excess of more than 750,000 households filed for bankruptcy between March 10, 2005 and October 17, 2005 relative to the counterfactual time-series. To calculate the net effect of BAPCPA on filings, we subtract the excess filings before the implementation of the law.

The more than 750,000 excess filings ahead of implementation suggest that debtors and their attorneys anticipated the changes to the bankruptcy code to be significant. Due to the mandated waiting period between filings, those who file for bankruptcy must do so because the benefits of filing today must exceed the loss of the option to file at another point in the future. ${ }^{26}$ For debtors who rushed to file before the new bankruptcy code went into effect, we can infer that the benefit

\footnotetext{
${ }^{26}$ Before BAPCPA, filers needed to wait 6 years after a Chapter 7 bankruptcy before filing again. BAPCPA increased that waiting period to 8 years, a change that Appendix Figure A1 demonstrates was binding for the small share of filers who file more than once.
} 
from filing for bankruptcy under the previous system exceeded the option value of waiting and potentially filing for bankruptcy under the new system.

On net, the decline in filings after implementation exceeds the pre-implementation increase in filings by July of 2006. Appendix Table A5 presents the difference for each 30 -week period between the predicted and the realized number of filings from the bill's passage in the Senate through the end of 2007. The temporary "rush-to-file" effect was quickly overwhelmed by the sustained reduction in filings under the new bankruptcy regime. Appendix Table A6 presents a range of estimates of the number of filings deterred by BAPCPA, showing sensitivity to alternative approaches to fitting the counterfactual time-series and controlling directly for the national unemployment rate. The results are qualitatively similar across the different approaches, and the range of estimates collectively suggest that roughly one million filings were deterred by the end of 2007 after netting out the rush-to-file effect.

\subsection{Composition of Filings}

The previous subsection establishes that BAPCPA clearly decreased the overall number of filings, but the introduction of the means test also sought to shift more filings from "fresh start" bankruptcies (Chapter 7) to "repayment-plan" bankruptcies (Chapter 13). Appendix Figure A3 plots the time-series for total filings separately for Chapter 7 and Chapter 13. Both Chapter 7 and Chapter 13 filings decline, and a means-test-driven shift from Chapter 7 to Chapter 13 does not appear to be the primary impact of the reform. However, the decline in filings is larger among Chapter 7 filings, so the share of filings that were Chapter 13 remained persistently higher after the reform, as is clear from Appendix Figure A4. Appendix Table A6 estimates the net change in overall filings through 2007 and shows that both Chapter 7 and Chapter 13 filings declined substantially.

A key goal of bankruptcy reform was to deter high-income filers from accessing bankruptcy relief "opportunistically." By excluding households with income above the state median from the option to liquidate their debts, the law intended to limit the bankruptcy code's most generous provisions to lower-income filers. If the means test was an important force altering the composition of filers, we would expect to see the income of the average filer decrease.

While much attention has been given to the means test, the reform's collective impact on the 
composition of filers is ambiguous a priori. ${ }^{27}$ BAPCPA also made a number of additional changes to the bankruptcy-filing process which collectively increased both the hassle costs of filing (through mandated credit counseling and financial management courses) and the liquidity requirements to file (through increased filing and attorney fees). The increased liquidity requirements to file, especially, may have deterred lower-income filers. Thus, the overall impact of the reform on the income of filers depends on the relative effects of these provisions across the income distribution.

We examine how the income of filers evolved through the reform by merging the filer's ZIP Code in the PACER sample with the median income for that ZIP Code from the 2000 Decennial Census. Figure 3 plots the full distribution of median ZIP Code income among filers for each year from 2004 through 2007. The distributions are strikingly similar-percentiles are virtually on top of each other through the $60^{\text {th }}$ percentile, at which point the post-BAPCPA incomes drift slightly upward. While these results provide suggestive evidence against the targeting that policymakers had in mind, the ZIP Code median income may be a poor proxy for bankruptcy filers' true income. ${ }^{28}$ We thus supplement this analysis with Appendix Figure A5 which, in Panel A, plots the mean income of filers using PACER bankruptcy filings which were merged with microdata on their income in the prior year from the American Community Survey and Decennial Census. ${ }^{29}$ Panel B plots an analogous trend using the average median ZIP Code income of weekly PACER filings, which suggests this may be an appropriate proxy. While there is a small dip in the mean income of bankruptcy filers in 2006, incomes quickly grow to exceed the pre-BAPCPA period and it does not appear that the results in Figure 3 are masking large within-ZIP-Code changes in the incomes of filers. Finally, Appendix Figure A6 shows that, despite the means test, these patterns are similar if we split by the chapter of filing.

Overall, we find no evidence to suggest the means test had a large effect on the income composition of bankruptcy filers. This is consistent with anecdotal reports from bankruptcy attorneys (Littwin, 2016) and other evaluations of the reform and the income of bankruptcy filers (Ashcraft et al., 2007; Lawless et al., 2008; Albanesi and Nosal, 2018; Fisher, 2019). One potential explanation is

\footnotetext{
${ }^{27}$ Several papers have used the means test to study the effects of BAPCPA and bankruptcy more generally. See, for example, the work of Li et al. (2011), Mahoney (2015), Mitman (2016), and Parra (2018).

${ }^{28}$ For example, Adelino et al. (2016) emphasize the importance of measuring the income of the households, not ZIP Codes, that take on mortgages for understanding the debt burdens in the run-up to the mortgage crisis.

${ }^{29}$ Our analysis of this dataset was part of a prior project and completed in Census Research Data Centers.
} 
Figure 3. ZIP Code Income Distribution of Bankruptcy Filers

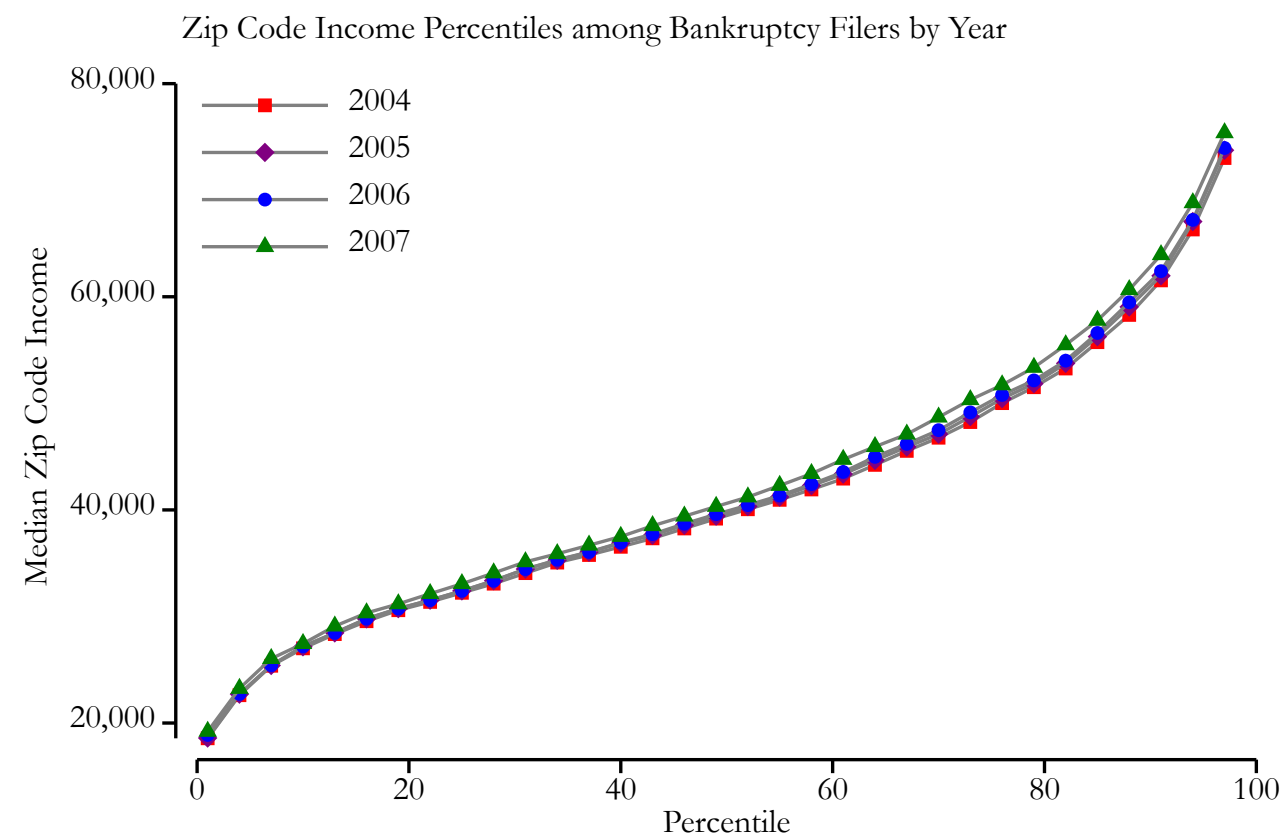

Notes: The sample consists of all consumer bankruptcy filings included in the PACER sample from January 2004 through December 2007, matched with the ZIP Code median household income measured in the 2000 decennial census. The figure plots the percentiles of ZIP Code median household income among filers for each year of 2004 through 2007.

that high-income households who would benefit from filing for bankruptcy could evade the means test by reducing their income in the six months prior to filing for bankruptcy either to qualify for Chapter 7 or to reduce their Chapter 13 repayment obligation by $\$ 10$ for every $\$ 1$ reduction in income above expenses, which may have made the means test less binding than policymakers desired.

\section{Effects of Bankruptcy-Filing Risk on Interest Rates}

In determining interest rates, creditors must predict the expected repayment rates on the credit they offer. Repayment rates, in turn, depend on the probability that a borrower will discharge their debt through bankruptcy. As suggested by the model in Section 3, reducing the generosity of the bankruptcy system ought to increase prospective repayment rates, and thus decrease the cost of lending. In this section, we test whether this decrease in the cost of lending was passed through to borrowers in the form of lower interest rates on credit-card offers.

We focus on credit-card offers for three reasons. First, credit cards are the most common method 
of borrowing in the United States. Roughly 75 percent of Americans have at least one credit card (65 percent of whom carry a balance) and total revolving debt was over $\$ 800$ billion for most of our sample period (Fulford and Schuh, 2015; Schuh and Stavins, 2015). Second, because creditcard debt is not secured, it is the most likely to be discharged in bankruptcy and thus the most responsive type of credit to changes in the bankruptcy code. Third, the Mintel dataset provides a clean measure of the prices at which lenders are willing to supply credit to households in the credit-card market, allowing us to overcome measurement challenges associated with other data sources. ${ }^{30}$

We are interested in identifying the change in borrowing costs $(d r)$ for a given change in bankruptcy-filing risk $(d p)$. We face the immediate challenge that BAPCPA was a national reform, which makes it hard to assess how borrowing costs would have evolved absent BAPCPA and distinguish the effects of BAPCPA from other national changes occurring around the same time. The key observation that gives rise to our empirical approach is that the bankruptcy risk of a potential borrower varies substantially with their credit score, and BAPCPA is associated with changes in bankruptcy risk that vary substantially across the credit score distribution.

This is evident in Figure 4, which plots the probability that borrowers across 40 equally sized credit-score segments file for bankruptcy over the next 12 months. Filing risk conditional on creditscore segment decreased significantly after the new bankruptcy code was implemented, but this decline was concentrated in the lower end of the credit score distribution. Credit scores above the median had a pre-BAPCPA bankruptcy-filing risk of less than 0.3 percent, which left little room to decline further. By contrast, subprime borrowers experienced a one-to-two-percentage-point decline in their bankruptcy-filing rate in the months that followed the implementation of BAPCPA. Our empirical strategy exploits variation in the effect of the reform on bankruptcy filings across the credit score distribution to identify the effects of BAPCPA on borrowing costs.

To parameterize the change in the probability of filing for bankruptcy across the credit score distribution, we define $\delta_{b}$ as the difference between the post-BAPCPA filing probability and the pre-BAPCPA filing probability for each 10-point credit-score segment. ${ }^{31}$ This provides us with a

\footnotetext{
${ }^{30}$ For instance, credit bureau data do not include prices. Other datasets, such as the National Mortgage Database, include information on prices only conditional on loan take-up.

${ }^{31}$ Given the very small share of debts that are recovered from bankruptcy filers, throughout the paper we focus
} 
Figure 4. Probability of Bankruptcy

12-Month Bankruptcy Filing Probability by Credit Score

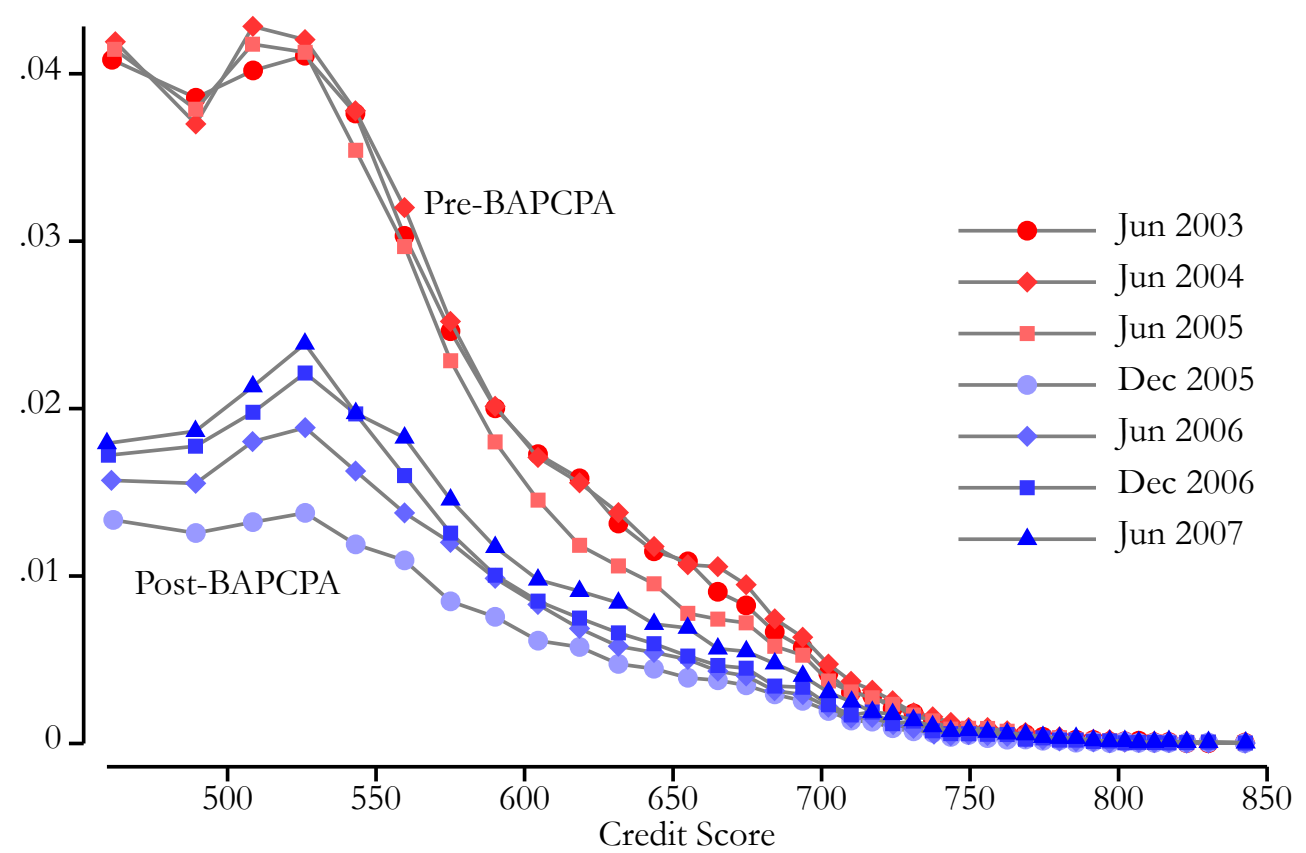

Notes: The sample consists of individuals with a non-missing credit score in the Consumer Credit Panel (CCP). This figure presents a binned scatter plot of the share of individuals who file for bankruptcy within the next 12 months. Each point represents the 12-month prospective filing rate for one of 40 equal-sized credit-score segments from the time of the credit report observation.

continuous treatment variable which we use to estimate pass-through as a function of the change in bankruptcy-filing risk. The exercise in Section 5 determines the overall net change in bankruptcy filings by accounting for those who rushed to file for bankruptcy before the law went into effect. By contrast, here we focus on changes in prospective bankruptcy filing rates. Lenders set prices based on their expectation of future bankruptcy filing rates, and so we use the actual changes in bankruptcy filings as a proxy for the expectations that lenders would have had regarding changes in bankruptcy rates. This proxy will be accurate if lenders formed rational and reasonably precise expectations about the changes in bankruptcy filings caused by BAPCPA.

We estimate the change in the prospective bankruptcy-filing risk by comparing the 12-month bankruptcy-filing rates for each credit-score segment before and after the reform. In particular, we take the average 12-month filing rate for each available quarter of the CCP before and after the

on the extensive margin of the bankruptcy-filing decision. BAPCPA also included provisions to increase repayment among bankruptcy filers, which we investigate in Appendix Section B.2.3. We find no evidence that repayment increased among bankruptcy filers, which justifies a focus on the filing decision as the relevant margin of adjustment. 
reform was implemented, and define $\hat{\delta_{b}}$ as the change in filing risk. ${ }^{32}$ We use this estimated change in bankruptcy-filing probability, $\hat{\delta_{b}}$, as our parameterization of the change in bankruptcy-filing probability we describe in Section 3 (i.e., $\frac{d p}{d c}$ ). This allows us to estimate the response of interest rates with respect to bankruptcy-filing rates, which maps to the comparative static of interest that we derived in the model above (i.e., $\left.\frac{d r}{d p}\right)$.

Our empirical strategy involves a comparison of different credit-score segments. We compare the changes in the interest rates offered to segments that experienced large declines in bankruptcyfiling risk to the interest rates offered to segments that experienced little change in bankruptcy-filing risk. That comparison isolates the object of interest $\left(\frac{d r}{d p}\right)$ as long as the change in bankruptcy risk across credit-score segments is not correlated with other time-varying determinants of interest rates. This assumption would be violated if, for instance, the credit-scoring formula itself were changing during this time period. Reassuringly, however, the credit-scoring formula was unchanged during this time period and the distribution of credit scores was quite stable (Appendix Figure A7). This assumption would also be violated if other dimensions of the credit-card contract were differentially changing for credit-score segments in ways we cannot observe and which affected the interest rates offered. Credit-card contracts are multidimensional, so changes to other contract features could also affect interest rates. Fortunately, the Mintel data allows us to observe and directly control for other dimensions of the credit-card contracts offered in order to isolate pass-through to interest rates. Appendix Figure A8 presents the time-series of interest rates (split by prime and subprime) which, while missing potentially important controls, suggests that interest rates were on similar trends and documents a similar pattern to the formal event-study analysis.

The Mintel data is a repeated cross-section and the level of observation is a credit-card offer. In our main specifications, we include year-month fixed effects $\left(\tau_{t}\right)$ to control for time trends common to all credit-card offers, credit-score-segment fixed effects to absorb time-invariant differences in prices across credit-score segments $\left(\phi_{b}\right)$, lender-specific fixed effects $\left(\nu_{j}\right)$ to absorb differences across

\footnotetext{
${ }^{32}$ We use the prospective 12-month filing rate for each of the time periods plotted in Figure 4 . To obtain the difference in the average between the pre-period observations (observed quarterly from September 2003 to September 2005, missing December 2003) and the post-period observations (observed quarterly from December 2005 to December 2007), we regress 12-month bankruptcy-filing risk by credit-score segment and quarter on indicator variables for each 10-point credit-score segment both on their own and interacted with an indicator variable for whether the observation occurred in the post-period. Appendix Table A7 presents the estimates $\hat{\delta_{b}}$.
} 
lenders, and fixed effects for other card features of offer $i\left(\chi_{i}\right) .{ }^{33}$ The estimating equation for the event study is:

$$
y_{i t}=\sum_{m=2004 m 1}^{2005 m 3} \beta^{m}\left(\hat{\delta_{b}} \times \tau_{m}\right)+\sum_{m=2005 m 5}^{2007 m 12} \beta^{m}\left(\hat{\delta_{b}} \times \tau_{m}\right)+\phi_{b}+\tau_{t}+\nu_{j}+\chi_{i}+\varepsilon_{i t} \text {. }
$$

The dependent variable $y_{i t}$ is the regular annual percentage rate (APR) of offer $i$ in month-year $t$. The variable $\hat{\delta_{b}}$ is the estimated difference in the propensity to file before and after passage of BAPCPA for credit-score segment $b$, which is used as a measure of "exposure" to the reform. This term is then interacted with an additional set of year-month fixed effects (for each year-month $m$ excluding the reference month April 2005 which is when BAPCPA was passed). The coefficients on each of these interaction terms represent the event-study dummies $\left(\beta^{m}\right)$ which are reported in the figures below. We weight all credit-card offers using Mintel-provided weights designed to make the sample representative of the overall mail volume. This allows us to estimate effects that are representative of the credit-card market as a whole. ${ }^{34}$ We report two-way cluster standard errors by credit-score segment and lender (Cameron et al., 2011). ${ }^{35}$

Figure 5 plots the coefficients of interest, $\hat{\beta^{m}}$ for each month $m$, with the regular APR as the dependent variable in equation (3). By allowing the event-study coefficients to evolve flexibly over time, this regression allows us to assess the assumption that interest-rate offers were evolving along parallel trends before the passage of BAPCPA. Further, by refraining from imposing any ex-ante restrictions on when interest rates should change, we can use the time pattern to gauge whether any changes in interest rates appear after the passage of BAPCPA but before the law's implementation.

In equilibrium, we would expect any changes to the bankruptcy code and interest rates to also affect borrowing behavior. We expect offered interest rates to respond immediately to anticipated

\footnotetext{
${ }^{33}$ The other features of the credit-card offers include fixed effects for whether the card has an introductory rate, an annual fee, a late fee, or a rewards program. They also include card category fixed effects for whether the card is securitized, an affinity card, co-branded, a lifestyle card, or a retail card. We also directly control for whether the offer was pre-approved, pre-qualified, pre-selected, guaranteed approval, or "general." Finally, we include fixed effects for the borrower's state-of-residence to account for potential state-level differences in the credit market.

${ }^{34}$ Mail volume represents the effective weight on each mail piece. For instance, the sum of all mail volume weights in the full Mintel data for Chase Freedom cards in a given month should equal the total mailings for Chase Freedom in that month, nationwide. In practice, the weights do not meaningfully affect the coefficients.

${ }^{35}$ While the treatment varies by credit-score segment, we report these two-way cluster standard errors because they are more conservative. Note that we ignore estimation error in $\delta_{b}$ when calculating standard errors, but we do not expect this to lead to meaningful bias in statistical inference since there is virtually no sampling error in our estimate of $\delta_{b}$ since it is calculated as the difference between two sample means using the very large CCP data set.
} 
Figure 5. Effect of Decline in Filing Probability on Offered Interest Rates

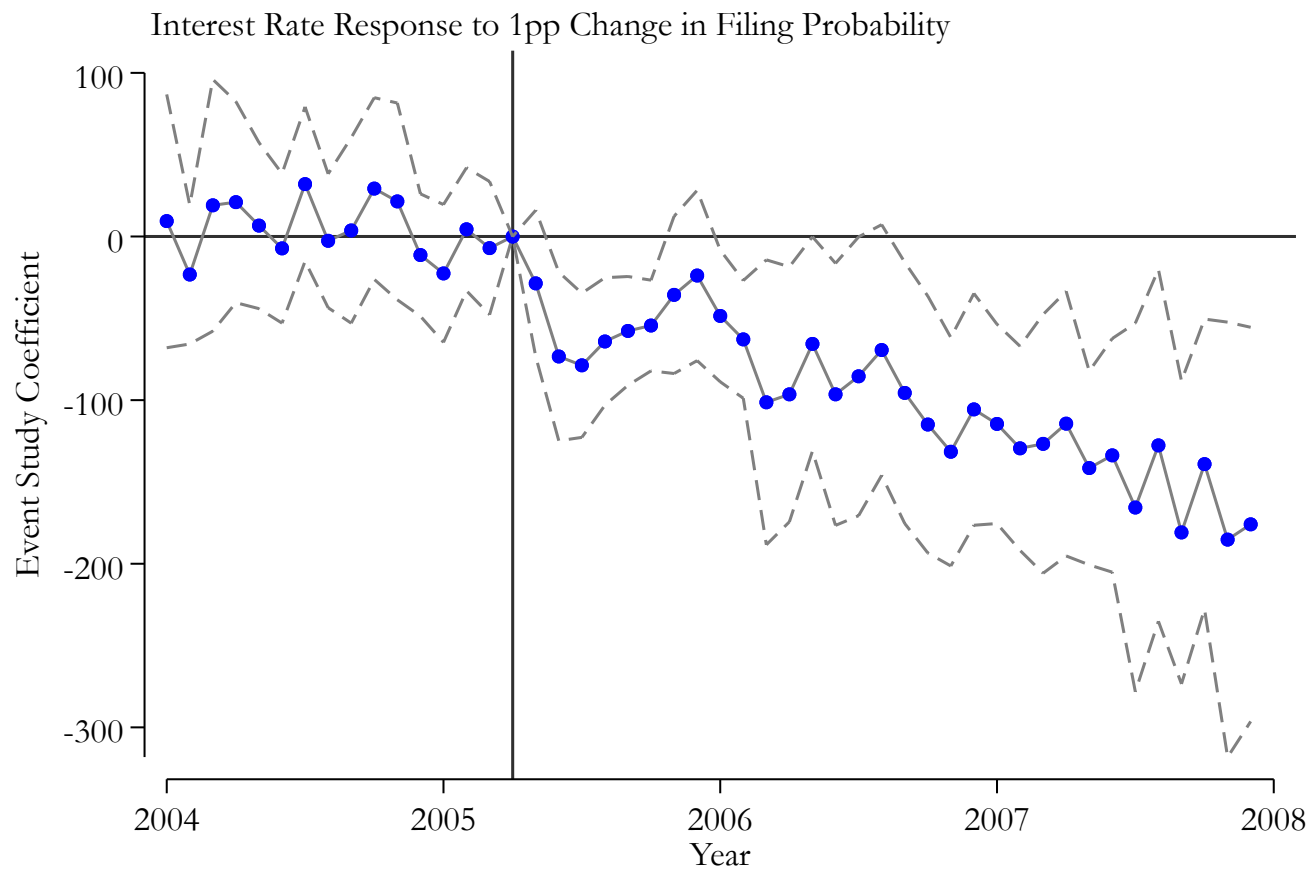

Notes: The sample consists of credit card offers made between January 2004 and December 2007 included in the Mintel data. The points represent estimates of the $\beta^{m}$ parameters in equation (3). Standard errors are two-way clustered by credit-score segment and lender and the dashed lines provide the 95-percent confidence interval for each point. The dependent variable is the regular offered interest rate.

changes in bankruptcy-filing probability, while any secondary effect on borrowing would take longer. Therefore, we are particularly interested in whether there exists a break in the evolution of interestrate offers when BAPCPA was signed into law. We focus on the timing of passage (rather than implementation) here because the bankruptcy code considers debts incurred in the months just before filing to be non-dischargeable; therefore, creditors could safely assume new lines of credit opened between passage and implementation would be unlikely to be discharged before the new bankruptcy code took effect.

Figure 5 suggests a decline in offered interest rates ahead of BAPCPA's implementation. While interest rates evolved similarly for the credit-score segments affected and unaffected by the reform throughout the pre-period, we observe a sharp drop in the $\beta^{m}$ estimates following the passage of BAPCPA in April 2005. The decline in interest rates among the credit-score segments that experienced a decline in the probability of filing for bankruptcy is stark and persistent - the interestrate spread drops immediately upon passage of BAPCPA and remains below the pre-period level 
through the post-period.

Motivated by the pattern in Figure 5, we estimate a difference-in-difference regression to quantify $\frac{d r}{d p}$. Specifically, we estimate the change in offered interest rates for a one-percentage-point decline in the 12-month probability of filing for bankruptcy:

$$
y_{i t}=\beta^{D D}\left(\hat{\delta_{b}} \times \mathbb{1}\{\text { Post-BAPCPA }\}\right)+\phi_{b}^{\prime}+\tau_{t}^{\prime}+\nu_{j}^{\prime}+\chi_{i}^{\prime}+\varepsilon_{i t}^{\prime},
$$

where, again, $\hat{\delta_{b}}$ is the difference in the probability of filing before and after the passage of BAPCPA and $\tau_{t}^{\prime}, \nu_{j}^{\prime}, \phi_{b}^{\prime}$, and $\chi_{i}^{\prime}$ are fixed effects for year-month, lender, credit-score segment, and offer features of the credit-card offer. In lieu of the month-year indicators interacted with $\hat{\delta_{b}}$ as in the event-study specification, we interact $\hat{\delta_{b}}$ with a "Post-BAPCPA" indicator (defined as $\mathbb{1}\{t \geq 2005 m 5\}$ ) for the offer coming after the BAPCPA was signed into law. As with the event-study specification, offers are weighted by mail volume and standard errors are two-way clustered by credit-score segment and lender.

Table 2 presents the coefficients of interest, $\beta^{D D}$, from equation (4). The baseline specification in column 3 includes fixed effects for each month-by-year, credit-score segment, lender, card category, contract feature, and application type. In order to control for other factors that may have changed differentially by credit-score segment, such as the expansion of the subprime market, we include prime- and subprime-specific month-year fixed effects starting in column 4. The main coefficient estimates are stable through the addition of these flexible controls for prime- and subprime-specific time-trends as well as the incremental inclusion of card category, application type, and state-specific fixed effects.

Secular trends in credit markets present potential confounding factors to our estimates. With the inclusion of month-year fixed effects, such trends only confound our estimates if they differentially affect borrowers of different credit scores. By including month-year-by-subprime fixed effects, we additionally control for arbitrary trends separately for prime and subprime borrowers. ${ }^{36}$ Given

\footnotetext{
${ }^{36}$ One specific concern is that BAPCPA was passed in the middle of a protracted rise in the Federal Funds Rate (FFR). While differential pass-through of the FFR to prime and subprime borrowers are subsumed by month-yearby-subprime fixed effects, we additionally report results in Appendix Table A8 from a specification which controls for an interaction between the FFR and an indicator for subprime status. The results are somewhat attenuated but similar to those presented in Table 2. We prefer the results with month-year-by-subprime effects since these results control for additional factors affecting prime and subprime credit market during this time period beyond any
} 
Table 2. Pass-through of Change in Bankruptcy-Filing Probability to Interest Rates

\begin{tabular}{|c|c|c|c|c|c|c|}
\hline & $(1)$ & $(2)$ & $(3)$ & $(4)$ & $(5)$ & $(6)$ \\
\hline & \multicolumn{6}{|c|}{ Panel A: Sample Period 2004 through 2007} \\
\hline$\hat{\delta_{b}} \times \mathbb{1}\{$ Post-BAPCPA $\}$ & $\begin{array}{c}-101.3^{* * *} \\
(35.7)\end{array}$ & $\begin{array}{c}-100.3^{* *} \\
(38.5)\end{array}$ & $\begin{array}{c}-100.5^{* *} \\
(38.4)\end{array}$ & $\begin{array}{c}-94.04^{* *} \\
(40.0)\end{array}$ & $\begin{array}{c}-90.0^{* *} \\
(33.7)\end{array}$ & $\begin{array}{c}-90.3^{* *} \\
(33.4)\end{array}$ \\
\hline $\mathrm{R}^{2}$ & 0.43 & 0.61 & 0.61 & 0.43 & 0.61 & 0.61 \\
\hline $\mathrm{N}$ & 391,153 & 379,967 & 379,382 & 391,153 & 379,967 & 379,382 \\
\hline \multirow[b]{2}{*}{$\hat{\delta_{b}} \times \mathbb{1}\{$ Post-BAPCPA $\}$} & \multicolumn{6}{|c|}{ Panel B: Sample Period 2004 through 2006} \\
\hline & $\begin{array}{c}-86.3^{* * *} \\
(27.3)\end{array}$ & $\begin{array}{c}-84.2^{* * *} \\
(28.3)\end{array}$ & $\begin{array}{c}-84.5^{* * *} \\
(28.4)\end{array}$ & $\begin{array}{c}-77.9^{* *} \\
(29.3)\end{array}$ & $\begin{array}{c}-71.5^{* * *} \\
(24.3)\end{array}$ & $\begin{array}{c}-72.0^{* * *} \\
(24.2)\end{array}$ \\
\hline $\mathrm{R}^{2}$ & 0.44 & 0.62 & 0.62 & 0.44 & 0.62 & 0.62 \\
\hline $\mathrm{N}$ & 307,288 & 298,867 & 298,403 & 307,288 & 298,867 & 298,403 \\
\hline \multicolumn{7}{|l|}{ Fixed Effects: } \\
\hline 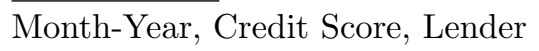 & $\checkmark$ & $\checkmark$ & $\checkmark$ & $\checkmark$ & $\checkmark$ & $\checkmark$ \\
\hline Category, Contract, Application & & $\checkmark$ & $\checkmark$ & & $\checkmark$ & $\checkmark$ \\
\hline State & & & $\checkmark$ & & & $\checkmark$ \\
\hline Month-Year by Subprime & & & & $\checkmark$ & $\checkmark$ & $\checkmark$ \\
\hline \multicolumn{7}{|c|}{$\begin{array}{l}\text { Notes: The sample consists of credit card offers made to households from January } 2004 \text { through December } 2007 . \\
\text { All columns report effects based on OLS estimates of equation }(4) \text { and include month-year, credit-score-segment, } \\
\text { and lender fixed effects in addition to the other fixed effects listed. The outcome variable is the interest rate on } \\
\text { credit card offers. Standard errors (two-way clustered by credit-score segment and lender) are in parentheses. } \\
\text { Offers are weighted by the mail volume of the campaign. Asterisks indicate significance at the } 1 \text { percent }(* * *) \text {, } \\
5 \text { percent }\left(*^{*}\right) \text {, and } 10 \text { percent }\left(^{*}\right) \text { level, respectively. }\end{array}$} \\
\hline
\end{tabular}

the increasing effect observed in Figure 5, one might also be concerned that the estimates are confounded by the emerging financial crisis leading up to the Great Recession. To address that concern, Panel B of Table 2 presents results based on restricting the post-period through December of 2006 (instead of December of 2007). The magnitudes of the effects are slightly smaller but similar in magnitude, suggesting that the bulk of the treatment effect we estimate emerged prior to the start of the financial crisis.

In addition to those robustness checks, we also assess whether there were corroborating trends in credit-card repayment rates. When the option to file for bankruptcy becomes less generous, we expect borrowers to be more likely to repay their loans and therefore, lenders to lower interest rates. We test this mechanism by studying repayment rates for new credit-card loans originated over our sample period using tradeline-level data from the CCP. We define loan cohorts based on

differential effects of the FFR. 
the month of origination and the credit score at origination, then examine the share of loans that are 60-plus days delinquent or in default in each of the following 18 months. Appendix Figure A9 presents the loan performance results for all borrowers by month of origination and shows a marked decline in defaults and delinquencies around the passage of BAPCPA. In decomposing this improved loan performance by prime and subprime borrowers, it becomes clear that the effect is driven by subprime borrowers whose default rates fall from 15.4 percent pre-BAPCPA to 12.3 post-BAPCPA (see Appendix Table A9). These borrowers were most affected by BAPCPA and provides corroborating evidence that the interest-rate response we observe is associated with real changes in loan performance, consistent with the results of Table 2.

Our preferred estimates of the relationship between interest rates and bankruptcy-filing risk come from the most demanding specifications in Table 2: a $72-90$-basis-point decline in the interest rate for each one-percentage-point decline in the 12-month prospective bankruptcy-filing risk. To interpret the magnitude of this estimate, we can scale the coefficient estimate by the average decline in bankruptcy-filing rate of 1.75 percentage points among subprime borrowers. This leads to a subprime market-wide reduction in offered interest rates of approximately 126-158 basis points, which narrows the spread on offered interest rates between prime and subprime borrowers by $12-15$ percent.

We can use the calibration results in Section 3 to assess the magnitude of these estimates. The perfect-competition benchmark for $\frac{d r / d c}{d p / d c}$, above, is 80-113 basis points for each one-percentagepoint change in filing risk. The estimates of equation (4) are either below or in the lower end of the range of this benchmark. While this exercise is not a conclusive statement on the competitiveness of credit-card markets, it does suggest that our estimates of pass-through are of reasonable magnitude and consistent with some competitive pricing pressure. Appendix Section B.3.3 analyzes passthrough separately by lender and finds results consistent with the heterogeneity in risk-based pricing documented by Stango and Zinman (2015).

In addition to examining the effects on offered interest rates, we can also look at other dimensions of the credit-card offer. Ru and Schoar (2016) argue that when unsophisticated borrowers are better credit risks, lenders rely on back-loaded features such as late fees and teaser rates. Appendix Table A10 presents results for whether the offer has an annual fee, rewards program, or introductory 
rate, late and annual fees, and the interest rate adjusted for any introductory rate. ${ }^{37}$ Appendix Figure A10 presents corresponding event-study figures. We estimate fairly precise zeroes for the the presence of annual fees, rewards programs, and introductory rates and the magnitude of late and annual fees. The estimated effect for the adjusted interest rate is smaller than the effect for the regular interest rate due to the mechanically lower weight on the interest rate when accounting for introductory rates and the small negative effect on the share of offers including an introductory rate, but it is otherwise consistent with the results of Table 2. Credit limits would have been an interesting additional outcome to study, but unfortunately they are not reliably measured in the Mintel data during our sample period. ${ }^{38}$

We might also expect less generous bankruptcy to lead to an extensive-margin increase in the supply of credit. Survey respondents are included in the Mintel data only in months when they forwarded at least one mailing they received. We follow Han et al. (2018) in defining a variable which takes the value of one if a respondent received a credit-card offer in a month and zero if a respondent received any other type of credit offer but not a credit-card offer. ${ }^{39}$ We run an individuallevel version of our baseline regression for whether an individual received a credit-card offer in a given month and present the results in Appendix Table A11. We find suggestive evidence of an extensive-margin increase in credit-card offers: a one-percentage-point decline in the probability of filing for bankruptcy increases the probability of receiving an offer in a given month by between 3 and 6 percentage points. 75 percent of subprime respondents receive a credit-card offer in a month on average, so these estimates represent an increase of 4 to 8 percent. While these effects are in the direction one would expect, we encourage caution in interpreting these results because of the structure of the Mintel data.

These decreases in offered interest rates benefit consumers to the degree that they take advantage

\footnotetext{
${ }^{37}$ We take a weighted average of the introductory (teaser) interest rate and the regular interest rate over the first 12 months after origination following Gross et al. (2020).

${ }^{38}$ About 91 percent of our Mintel credit-card offers are missing either the minimum credit limit or maximum credit limits in our data. As Han et al. (2018) note in their paper, there was a change in industry practice during our sample period from reporting maximum credit limits to minimum credit limits. They were able to analyze the effects of the 2009 CARD Act on minimum credit limits using Mintel data, but minimum credit limits are missing for all credit-card offers in our pre-BAPCPA period. Maximum credit limits are missing in such an unbalanced way across the sample period as to make any estimates unreliable.

${ }^{39}$ These include offers for auto loans, education loans, home equity loans, mortgages and reverse mortgages, and unsecured loans. The number of individuals with an offer that is not a credit card varies substantially over the sample period from 60.4 to 76.3 percent for all respondents and from 44.8 to 68.0 percent for subprime respondents. Additional details are provided in Appendix Section B.3.1.
} 
of the lower rates. Consumers may not be especially strategic in doing so. Stango and Zinman (2015) and Woodward and Hall (2012) document substantial dispersion in borrowing costs that appear to be driven by consumers partaking in too little price-shopping. Similarly, Keys and Wang (2019) and Gathergood et al. (2019) document that consumers tend to repay their credit-card debt based on anchoring and heuristics rather than minimizing borrowing costs. Finally, Nelson (2018) documents that interest rates can drift upward after origination, which could mitigate some of the benefits of lower interest rates (particularly for borrowers whose credit scores worsen after origination). Nevertheless, as long as consumers borrow using unsecured credit, the decrease in interest rates at origination as a result of BAPCPA is likely to have provided them with meaningful savings.

\section{Effects of BAPCPA on the Insurance Value of Bankruptcy}

The overall welfare effects of BAPCPA depend on the trade-off between individuals' gain from lower borrowing costs and their loss from reducing the insurance value of bankruptcy. In this section, we ask how adverse shocks (specifically, health shocks requiring hospitalization) were insured by bankruptcy before and after the reform.

In the debate over bankruptcy reform, many expressed concern over how the reform might affect the insurance value of bankruptcy. Warren (2005) argued against BAPCPA because the means test would "treat all families alike... A person who had a heart attack is treated the same as someone who had a spending spree at the mall."

This distinction between bankruptcies driven by medical costs and bankruptcies driven by discretionary consumption is present in life-cycle models of the bankruptcy decision. ${ }^{40}$ Livshits et al. (2007) demonstrate that the existence of expense shocks, such as medical costs, can make "fresh start" (Chapter 7) bankruptcy regimes welfare-increasing despite increasing the cost of borrowing. Particularly when markets are incomplete, bankruptcy may be the only mechanism by which an individual can insure some negative events. We thus seek to estimate whether specific expense

\footnotetext{
${ }^{40}$ Divorce, job loss, and unplanned pregnancies are additional shocks that are discussed as relevant to the welfare implications of the bankruptcy code (Livshits et al., 2007; Fay et al., 2002; Keys, 2018), though medical expenses are often pointed to as the most "blameless."
} 
shocks were differentially insured by bankruptcy after the reform. ${ }^{41}$ To do so, we estimate the likelihood that individuals experiencing hospitalization shocks declare bankruptcy to obtain debt relief before and after changes to the bankruptcy code.

We use the universe of uninsured hospitalizations between 2003 and 2007 in California, where approximately 20 percent of residents lacked insurance during that time (California Healthcare Foundation, 2013). For comparison, we also study insured hospitalizations in parallel for individuals private health insurance or Medicaid coverage. Each hospitalization is linked to the patient's credit reports, which we observe in January of each year from 2002 through 2011. We limit the sample to adults aged 25-64 who were not hospitalized in the three years prior to their hospitalization to isolate "health shocks." 42

In an ideal experiment, we would randomly assign different bankruptcy regimes to otherwiseidentical individuals experiencing a health shock. In our setting, one might be concerned that the composition of uninsured hospitalizations is different before and after the reform. ${ }^{43,44}$ By isolating health shocks for individuals who have not been hospitalized in the previous three years, we come closer to approximating this experiment. Hospitalizations are much less likely to be anticipated than other sources of health insurance demand, such as chronic conditions requiring outpatient care.

To further address this concern, we re-weight the two sets of hospitalizations on their observable characteristics, though this has little effect on our estimates. We use propensity score matching to re-weight those hospitalized in each period in order to match them on age, sex, race, ZIP Code

\footnotetext{
${ }^{41}$ While perhaps the most natural interpretation of the health shocks we study is a shock to medical expenses, Dobkin et al. (2018a) show that health shocks requiring hospitalization lead to both increases in out-of-pocket medical costs as well as decreases in income and earnings. Both of these changes increase the financial benefit of filing for bankruptcy, so the health shocks leading to hospitalizations should more accurately be viewed as a combination of expense shocks and income shocks.

${ }^{42}$ The precipitating event will be a hospitalization, but estimated effects of the hospitalization will include all sequelae (e.g., subsequent hospitalizations, lost earnings).

${ }^{43}$ As observed by Mahoney (2015), changes in the bankruptcy code also changes the incentives for individuals to purchase health insurance. This generates a concern that uninsured health shocks would be differentially selected before and after BAPCPA. Two patterns in the data ameliorate these concerns. First, at least in a coarse examination of the data, the share of Californians without health insurance was broadly unchanged over our sample period (California Healthcare Foundation, 2013). The estimated share of individuals lacking health insurance in California in each year from 2003 through 2007 held steady between 19 and 20 percent. Second, we estimate that at least as much medical debt is sent to collections for post-BAPCPA hospitalizations (Panel A of Table 3).

${ }^{44}$ A related concern is that California implemented the "Hospital Fair Pricing Act" in 2007 which required hospitals to offer discounts or charity care to individuals making less than 350 percent of the Federal Poverty Line. Figure 7 plots the implied effects by the quarter-year of hospitalization, and shows the results within the post-period do not look dramatically different between 2006 and 2007 hospitalizations.
} 
median household income, whether the hospitalization was for a chronic condition, and on the major diagnostic category. Appendix Table A4 presents summary statistics by insurance status and hospitalization period.

Following Dobkin et al. (2018a), we estimate event-study regressions, and we build on this work by additionally splitting the sample by whether the hospitalization occurred under the pre- or post-BAPCPA bankruptcy regime. We define the pre-BAPCPA period to be January 2003 through December 2004 and the post-BAPCPA period to be from October 2005 through December $2007 .{ }^{45}$

We define event time, $m$, as the number of months relative to the hospitalization, which occurs at $m=0$, and $q$ indexes whether the hospitalization occurred in the pre-BAPCPA period $(q=0)$ or post-BAPCPA period $(q=1)$. Omitting the month prior to the hospitalization $(m=-1)$ and including calendar-year-specific fixed effects, we specify a non-parametric event-study regression to estimate the evolution of the outcome variable preceding and following the hospitalization:

$$
y_{i t}=\gamma_{t}+\sum_{q \in\{0,1\}}\left(\sum_{m=-24}^{-2} \mu_{m q}+\sum_{m=0}^{48} \mu_{m q}\right)+\varepsilon_{i t}
$$

In order to estimate how frequently a hospitalization leads to bankruptcy, we also estimate a parametric event-study specification. This allows us to calculate the "implied effect" at each month relative to the hospitalization. We allow for a linear pretrend in event time $m$ (months relative to admission) and a flexible cubic spline with breaks at 0,12 , and 24 months in the post-period. These allow us to estimate the effect of the hospitalization at any point, separately by the hospitalization period:

$$
y_{i t}=\gamma_{t}+\sum_{q \in\{0,1\}}\left(\beta_{0 q} m+\beta_{1 q} m^{2}\{m>0\}+\sum_{s=0}^{2} \beta_{(s+2) q}(m-12 s)^{3}\{m>12 s\}\right)+\varepsilon_{i t} \text {. }
$$

Figure 6 suggests that the parametric spline fits the non-parametric event-study coefficients well. The identifying assumption requires that, separately for pre-BAPCPA and post-BAPCPA hospitalizations, conditional on having a hospital admission and jointly estimated calendar-year fixed effects, the timing of the admission is uncorrelated with deviations of the outcome from a

\footnotetext{
${ }^{45}$ Note that those hospitalized later in the pre-BAPCPA period have less exposure to the pre-BAPCPA regime, which may attenuate any differences between the pre- and post-BAPCPA estimates.
} 
Figure 6. Effect of Hospitalization on Bankruptcy Filing

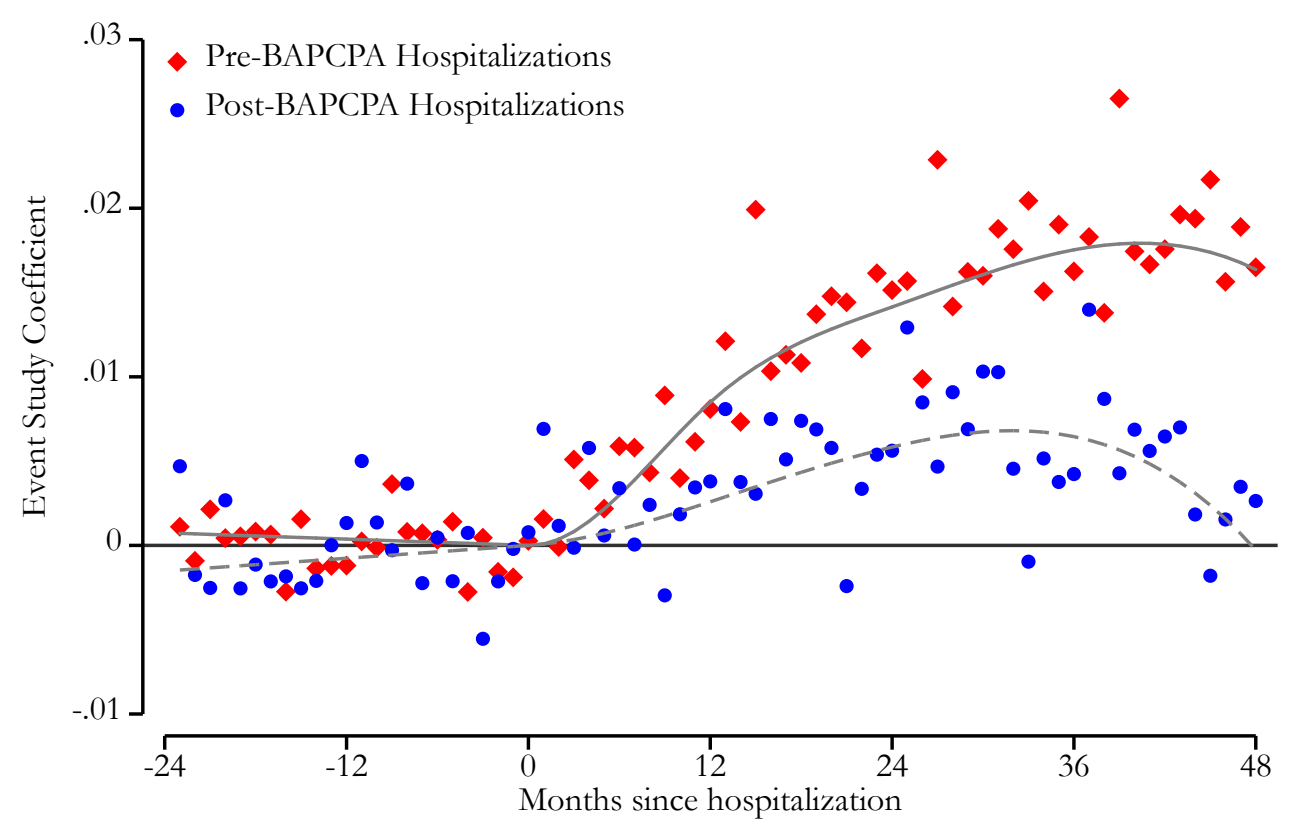

Notes: The sample consists of individuals aged 25-64 who are hospitalized without insurance in California, additionally split by the timing of the hospitalization (January 2003 through December 2004 for the pre-BAPCPA sample, October 2005 through December 2007 for the post-BAPCPA sample). The points represent the estimated effects of event time (i.e., the $\mu_{m} q$ estimates from the non-parametric event study in equation (5)) and the lines represent the parametric event study in equation (6).

linear trend in event time.

Figure 6 presents the results of both event studies for the probability an uninsured hospitalization resulted in a bankruptcy filing. The red diamond markers trace the path of individuals hospitalized in the pre-BAPCPA environment, while the blue circle markers trace the path of those hospitalized in the post-BAPCPA environment. The pre-BAPCPA hospitalizations result in a pronounced spike in bankruptcy filings following hospitalization, increasing starkly around the time debt is typically sent to collections (around 180 days after the hospitalization). The rate of filings remains persistently higher for the subsequent four years. By comparison, those hospitalized after changes to the bankruptcy code were implemented display a muted filing response to the hospitalization.

Table 3 provides estimates of the "implied effect" of the hospitalization at 12 and 24 months separately by bankruptcy regime and insurance coverage. The implied effect is the deviation of the parametric coefficients from the linear pretrend, which we interpret as the impact of the hospital- 
Table 3. Implied Effects of Hospitalization on Bankruptcy

\begin{tabular}{|c|c|c|c|c|}
\hline & (1) & $(2)$ & (3) & (4) \\
\hline Insurance Coverage: & \multicolumn{2}{|c|}{ Uninsured } & \multicolumn{2}{|c|}{ Insured } \\
\hline Hospitalization Period: & $\begin{array}{c}\text { Pre- } \\
\text { BAPCPA }\end{array}$ & $\begin{array}{c}\text { Post- } \\
\text { BAPCPA }\end{array}$ & $\begin{array}{c}\text { Pre- } \\
\text { BAPCPA }\end{array}$ & $\begin{array}{c}\text { Post- } \\
\text { BAPCPA }\end{array}$ \\
\hline & \multicolumn{4}{|c|}{ Panel A. Collections Balance } \\
\hline Implied Effect at 12 Months $^{\mathrm{a}}$ & $\begin{array}{l}4,559 \\
(105)\end{array}$ & $\begin{array}{l}5,163 \\
(135)\end{array}$ & $\begin{array}{l}103 \\
(28)\end{array}$ & $\begin{array}{l}178 \\
(29)\end{array}$ \\
\hline Implied Effect at 24 Months ${ }^{\text {b }}$ & $\begin{array}{l}6,724 \\
(169)\end{array}$ & $\begin{array}{l}6,944 \\
(229)\end{array}$ & $\begin{array}{l}163 \\
(53)\end{array}$ & $\begin{array}{l}316 \\
(57)\end{array}$ \\
\hline Pre-Hospitalization Mean & 2,869 & 3,994 & 1,068 & 1,341 \\
\hline & \multicolumn{4}{|c|}{ Panel B. Any Bankruptcy Filing } \\
\hline Implied Effect at 12 Months $^{\mathrm{a}}$ & $\begin{array}{l}0.89 \\
(.12)\end{array}$ & $\begin{array}{l}0.18 \\
(.08)\end{array}$ & $\begin{array}{l}0.19 \\
(.08)\end{array}$ & $\begin{array}{l}0.15 \\
(.05)\end{array}$ \\
\hline Implied Effect at 24 Months ${ }^{\text {b }}$ & $\begin{array}{c}1.49 \\
(0.23)\end{array}$ & $\begin{array}{c}0.43 \\
(0.15)\end{array}$ & $\begin{array}{c}0.37 \\
(0.15)\end{array}$ & $\begin{array}{c}0.25 \\
(0.10)\end{array}$ \\
\hline Pre-Hospitalization Mean & 2.11 & 4.94 & 2.07 & 4.38 \\
\hline$P$-value (12-Month Pre/Post Equality) & \multicolumn{2}{|c|}{$[<0.001]$} & \multicolumn{2}{|c|}{$[0.84]$} \\
\hline $\mathrm{N}$ & 53,611 & 62,912 & 164,207 & 145,502 \\
\hline
\end{tabular}

Notes: The sample consists of individuals aged 25-64 who are hospitalized in California, additionally split by the timing of the hospitalization (January 2003 through December 2004 for the pre-BAPCPA sample, October 2005 through December 2007 for the post-BAPCPA sample) and insurance coverage (uninsured or insured which includes those with private insurance or Medicaid coverage). All columns report effects based on OLS estimates of equation (6). The outcome variable is whether an individual has filed for bankruptcy since the beginning of the sample (January 2002). Standard errors (clustered on the individual) are in parentheses. The universe of qualifying uninsured hospitalizations are included in the sample; estimates for the insured are weighted to adjust for individuals' sampling probabilities. All implied effects are significant with p-values less than .015.

a The implied effect at 12 months is calculated from equation (6) as $144 \times \beta_{2}+1,728 \times \beta_{4}$

b The implied effect at 24 months is calculated from equation (6) as $576 \times \beta_{2}+13,824 \times \beta_{4}$

ization on the probability of filing for bankruptcy.

Uninsured hospitalizations result in a similar amount of debt sent to collections under both bankruptcy regimes but 70 percent fewer bankruptcy filings after the reform. Panel A of Table 3 shows the implied effect on debt sent to collections 24 months after the hospitalization increased were very similar before and after the reform $(\$ 6,700$ and $\$ 6,900$, respectively). This supports our assumption that we are comparing otherwise-similar individuals who experience similar health shocks but face different bankruptcy regimes. Panel B shows that uninsured hospitalizations were much less likely to be discharged through bankruptcy after the reform. At 24 months post-hospitalization, the pre-BAPCPA uninsured are 1.49 percentage points more likely to file for 
bankruptcy due to the hospitalization. After implementation, the implied effect of the hospitalization on filing for bankruptcy falls by 70 percent to just $0.43 .{ }^{46}$ The marked decline in the implied effect of a hospitalization on filing for bankruptcy indicates that bankruptcy reform significantly reduced the share of uninsured individuals who access bankruptcy as implicit health insurance.

We can additionally test whether these effects appear to be driven by BAPCPA by separately estimating implied effects for different cohorts of hospitalizations. Based on the event-study figures, most of the effect of the hospitalization occurs in the first 12 months post-hospitalization. Observing this, we additionally plot the implied effects at 12 months separately for each quarter-year-ofadmission cohort. We regress the parametric spline specification fully-interacted with indicators for the quarter-year-of-admission, jointly estimating calendar-year fixed effects across cohorts. Figure 7 presents the estimates and demonstrates that the effects described in this Section evolve tightly around the implementation of BAPCPA.

There was a large expansion of credit over this time period. Hurst and Stafford (2004) suggest that households tend to "cash out" home equity in order to smooth out negative shocks, so one may be concerned that the decline in bankruptcy filings was driven by increased substitution into borrowing. We perform three additional analyses to investigate this point. The evidence supports the view that changes to bankruptcy law were the predominant force. First, while credit limits and home-equity lines of credit, in particular, increased smoothly through this period, the 12month implied effects of an uninsured hospitalization on bankruptcy filing change tightly around the implementation of BAPCPA in Figure 7. Second, we repeat the event-study analysis for credit limits, borrowing, and home equity line of credit in Appendix Table A12. Hospitalizations cause credit limits to decrease in both the pre- and post-BAPCPA periods. Credit-card borrowing increases in the pre-period but declines in the post-period. A new home-equity line of credit is associated with a $\$ 40,000$ increase in credit limits in our sample, so these results do not suggest that individuals were turning to new borrowing instead of filing for bankruptcy. Finally, Appendix

\footnotetext{
${ }^{46}$ While the share of individuals eligible to file for bankruptcy is smaller post-BAPCPA, this is a mechanical result of the construction of a stock variable for ever filing for bankruptcy over the sample period. As further reassurance on this point, the insured demonstrate a similar increase in the share of individuals who have filed for bankruptcy in advance of their hospitalization (4.38 percent from 2.07 percent versus 4.94 percent from 2.11 percent for the uninsured) but a substantially smaller decline after the reform. Appendix Figure A11 plots the analog to Figure 6 for insured hospitalizations.
} 
Figure 7. Effect of Hospitalization on Bankruptcy Filing by Quarter of Admission

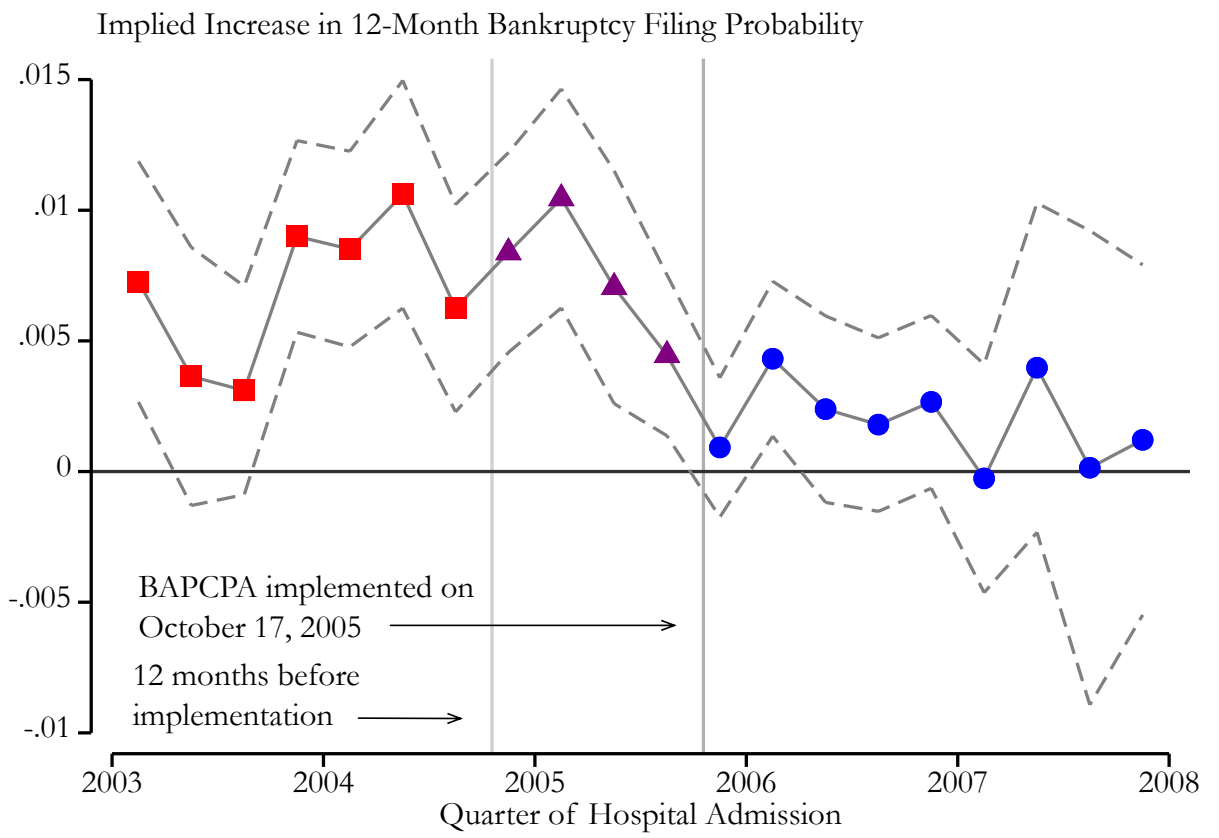

Notes: The sample consists of individuals aged 25-64 who are hospitalized without insurance in California between January 2003 and December 2007, additionally split by the quarter-year of admission to the hospital. The points represent the 12-month implied effects of the hospitalization on the likelihood an individual has filed for bankruptcy. Implied effects are estimated based on the parametric event study with year fixed effects jointly estimated and event-study coefficients separately estimated by quarter-year of admission. Standard errors are clustered on the individual and the dashed lines provide the 95-percent confidence interval for each point. The vertical lines indicate the date BAPCPA was implemented and 12 months before that date. Hospitalizations that occur between the two vertical lines are "partially exposed" to BAPCPA, since the outcome is whether individual files for bankruptcy during the first 12 months following admission to the hospital.

Figure A12 shows the likelihood of filing for bankruptcy in the next 12-months for a random sample of Californians in the pre- and post-BAPCPA years. That sample includes our hospitalizations sample in proportion to the population probability of hospitalization. We study the amount of debt in collections, credit-card balances, auto loan balance, credit utilization, and credit limit. If the decline in post-hospitalization bankruptcy filing were driven by substitution to other sources of borrowing, we would expect to see bankruptcy-filing rates change differentially for those with less access to credit. By contrast, Appendix Figure A12 shows that the decline in filing is observed uniformly across every level of each of these outcomes.

While hospitalizations in and of themselves may make up a small share of overall bankruptcy 
filings (Dobkin et al., 2018b), to the degree that uninsured health shocks can be generalized to other types of adverse shocks (including expenses shocks and shocks to income and earnings), these results suggest that BAPCPA meaningfully reduced the insurance value of bankruptcy.

\section{Conclusion}

The option to file for bankruptcy provides insurance to American households by providing a process to discharge their debts in response to adverse events; however, by limiting borrowers' ability to commit to repayment, bankruptcy increases interest rates and the cost of smoothing consumption over time. This paper uses a major change to the bankruptcy code in the United States to evaluate this trade-off empirically.

We find that the 2005 bankruptcy reform induced a net reduction of roughly one million bankruptcy filings in the two years after implementation, but we found no evidence that it meaningfully changed the composition of bankruptcy filers by income. We demonstrate that the reduction in the risk of bankruptcy filing induced by the reform was passed-through to consumers in the form of lower borrowing costs. Our results suggest that a one-percentage-point reduction in bankruptcyfiling risk leads to a 70-90-basis-point decline in offered credit-card interest rates. We use a simple model to calibrate a reasonable benchmark under perfect competition, and comparing our results to this benchmark suggests a large degree of pass-through. This is consistent with competitive pricing pressure in the credit-card market. Lastly, we find that those hospitalized without health insurance were less likely to declare bankruptcy after the reform. This suggests that BAPCPA decreased the insurance value of bankruptcy.

The overall welfare implications of BAPCPA depend on the trade-off between individuals' gain from lower borrowing costs and their loss from the reduced insurance value of the bankruptcy. To quantify the normative consequences of the reform would require, at the very least, quantifying the money-metric loss of the insurance value for the marginally deterred non-filers, as well as the gain from lower interest rates for the affected credit-score segments. This is an important area of future work, and the results in this paper can be used as inputs into structural models that carry out this type of welfare analysis (see, e.g., Mitman 2016; Nakajima 2017). Mitman (2016), for instance, finds an average welfare gain from BAPCPA of 0.12 percent of lifetime consumption and that 
households that file for bankruptcy have a welfare loss of 0.4 percent of lifetime consumption. ${ }^{47}$ However, Mitman (2016) abstracts from medical expenditures shocks and notes that "given the modest welfare gains in the model, it is possible that introducing expenditure shocks could overturn the net positive effect of the reform." The large reduction in the share of individuals with a health shock who obtain bankruptcy relief in Section 7 of the paper suggests that this could be the case in reality, particularly if our health-shock results are representative of other types of adverse shocks.

The continued study of BAPCPA is not just a matter of historical interest. Other major reforms are currently being proposed, and future changes to bankruptcy law seem likely. ${ }^{48}$ The United States offers its citizens a meager social safety net relative to other wealthy countries but has one of the most generous consumer bankruptcy systems in the world. In contrast to other social safety net programs, such as public health insurance or income-maintenance programs, which require large allocations of public funds, the consumer bankruptcy system requires little direct public funding. Instead, the insurance it provides is funded indirectly through higher interest rates. This paper provides evidence on the costs and benefits of a generous bankruptcy system by studying the effects of bankruptcy reform on bankruptcy rates, interest rates, and the insurance provided by the bankruptcy system. We hope these results inform future decisions of policymakers, who must grapple with the trade-offs that we highlight in this paper.

\footnotetext{
${ }^{47}$ Nakajima (2017) finds a similar 0.29 percent increase in lifetime consumption.

${ }^{48}$ For example, Senator Elizabeth Warren recently proposed a comprehensive set of bankruptcy reforms towards the end of her 2020 presidential campaign. See here for more details on Senator Warren's proposed reforms: https: //elizabethwarren.com/plans/bankruptcy-reform.
} 


\section{References}

Adelino, Manuel, Antoinette Schoar, and Felipe Severino, "Loan Originations and Defaults in the Mortgage Crisis: The Role of the Middle Class," The Review of Financial Studies, 2016, $29(7), 1635-1670$.

Agarwal, Sumit, Souphala Chomsisengphet, Neale Mahoney, and Johannes Stroebel, "Do Banks Pass Through Credit Expansions to Consumers Who Want to Borrow?," The Quarterly Journal of Economics, 2017, 133 (1), 129-190.

Albanesi, Stefania and Jaromir B Nosal, "Insolvency after the 2005 Bankruptcy Reform," National Bureau of Economics Research Working Paper \#24934, 2018.

Ashcraft, Adam B, Astrid Andrea Dick, and Donald P Morgan, "The Bankruptcy Abuse Prevention and Consumer Protection Act: Means-Testing or Mean Spirited?," Staff Report, Federal Reserve Bank of New York, 2007, 279.

Ausubel, Lawrence M, "The Failure of Competition in the Credit Card Market," American Economic Review, 1991, pp. 50-81.

Board of Governors, "Report to the Congress on Practices of the Consumer Credit Industry in Soliciting and Extending Credit and Their Effects on Consumer Debt and Insolvency," Washington, DC: Federal Reserve Board, 2006.

Cabral, Marika, Michael Geruso, and Neale Mahoney, "Do Larger Health Insurance Subsidies Benefit Patients or Producers? Evidence from Medicare Advantage," American Economic Review, 2018, 108 (8), 2048-87.

Calem, Paul S and Loretta J Mester, "Consumer Behavior and the Stickiness of Credit-Card Interest Rates," American Economic Review, 1995, 85 (5), 1327-1336.

_, Michael B Gordy, and Loretta J Mester, "Switching Costs and Adverse Selection in the Market for Credit Cards: New Evidence," Journal of Banking 85 Finance, 2006, 30 (6), $1653-1685$.

California Healthcare Foundation, "California's Uninsured: By the Numbers," Technical Report, California Healthcare Foundation 2013.

Cameron, A Colin, Jonah B Gelbach, and Douglas L Miller, "Robust Inference with Multiway Clustering," Journal of Business 83 Economic Statistics, 2011, 29 (2), 238-249.

Chakrabarti, Rajashri and Nathaniel Pattison, "Auto Credit and the 2005 Bankruptcy Reform: the Impact of Eliminating Cramdowns," The Review of Financial Studies, 2019, 32 (12), 4734-4766.

Chatterjee, Satyajit, Dean Corbae, Makoto Nakajima, and José-Víctor Ríos-Rull, "A Quantitative Theory of Unsecured Consumer Credit with Risk of Default," Econometrica, 2007, 75 (6), 1525-1589.

Chetty, Raj, John N Friedman, Tore Olsen, and Luigi Pistaferri, "Adjustment Costs, Firm Responses, and Micro vs. Macro Labor Supply Elasticities: Evidence from Danish Tax Records," The Quarterly Journal of Economics, 2011, 126 (2), 749-804. 
Dawsey, Amanda E and Lawrence M Ausubel, "Informal Bankruptcy," in "Twelfth Annual Utah Winter Finance Conference" 2002.

Dobkin, Carlos, Amy Finkelstein, Raymond Kluender, and Matthew J Notowidigdo, "The Economic Consequences of Hospital Admissions," American Economic Review, 2018, 108 (2), 308-52.

_ , _ , , and _ , "Myth and Measurement-The Case of Medical Bankruptcies," The New England Journal of Medicine, 2018, 378 (12), 1076.

Dubey, Pradeep, John Geanakoplos, and Martin Shubik, "Default and Punishment in General Equilibrium," Econometrica, 2005, 73 (1), 1-37.

Fabra, Natalia and Mar Reguant, "Pass-Through of Emissions Costs in Electricity Markets," American Economic Review, 2014, 104 (9), 2872-99.

Fay, Scott, Erik Hurst, and Michelle J White, "The Household Bankruptcy Decision," American Economic Review, 2002, 92 (3), 706-718.

Fisher, Jonathan D, "Who Files for Personal Bankruptcy in the United States?," Journal of Consumer Affairs, 2019, 53 (4), 2003-2026.

Fulford, Scott and Scott Schuh, "Consumer Revolving Credit and Debt Over the Life Cycle and Business Cycle," Technical Report 15-17, Federal Reserve Bank of Boston Research Department Working Papers 2015.

Gathergood, John, Neale Mahoney, Neil Stewart, and Jörg Weber, "How do Individuals Repay their Debt? The Balance-Matching Heuristic," American Economic Review, 2019, 109 (3), 844-75.

Grodzicki, Daniel, "The Evolution of Competition in the Credit Card Market," Working Paper, 2017.

Gross, Tal, Matthew J Notowidigdo, and Jialan Wang, "Liquidity Constraints and Consumer Bankruptcy: Evidence from Tax Rebates," Review of Economics and Statistics, 2014, 96 (3), 431-443.

_ , _, and _, "The Marginal Propensity to Consume Over the Business Cycle," American Economic Journal: Macroeconomics, 2020, 12 (2), 351-84.

Han, Song, Benjamin J Keys, and Geng Li, "Unsecured Credit Supply, Credit Cycles, and Regulation," The Review of Financial Studies, 2018, 31 (3), 1184-1217.

Herkenhoff, Kyle F and Gajendran Raveendranathan, "Who Bears the Welfare Costs of Monopoly? The Case of the Credit Card Industry.," National Bureau of Economic Research Working Paper \#26604, 2020.

Herring, Adam D., "Problematic Consumer Debtor Attorney's Fee Arrangements and the Illusion of "Access to Justice," American Bankruptcy Institute Journal, October 2018, XXXVII (10).

House Report, "Bankruptcy Abuse Prevention and Consumer Protection Act of 2005 Report of the Committee on the Judiciary House of Representatives to Accompany S. 246," Technical Report 109-31 April 2005. 
Hurst, Erik and Frank Stafford, "Home is where the Equity is: Liquidity Constraints, Refinancing and Consumption," Journal of Money, Credit and Banking, 2004, 36 (6), 985-1014.

Indarte, Sasha, "The Impact of Debt Relief Generosity and Liquid Wealth on Household Bankruptcy," Working Paper, 2018.

Jurgens, Rick and Chi Chi Wu, "Fee Harvesters: Low-credit, High-cost Cards Bleed Consumers," National Consumer Law Center Report, 2007.

Keys, Benjamin and Jialan Wang, "Minimum Payments and Debt Paydown in Consumer Credit Cards," Journal of Financial Economics, 2019, 131 (3).

Keys, Benjamin J, "The Credit Market Consequences of Job Displacement," Review of Economics and Statistics, 2018, 100 (3).

Kleven, Henrik Jacobsen, "Bunching," Annual Review of Economics, 2016, 8 (1), 435-464.

Lawless, Robert M, Angela K Littwin, Katherine M Porter, and John AE Pottow, "Did Bankruptcy Reform Fail-An Empirical Study of Consumer Debtors," American Bankruptcy Law Journal, 2008, 82, 349.

Li, Wenli, Michelle J White, and Ning Zhu, "Did Bankruptcy Reform Cause Mortgage Defaults to Rise?," American Economic Journal: Economic Policy, 2011, 3 (4), 123-47.

Littwin, Angela, "Adapting to BAPCPA," American Bankruptcy Law Journal, 2016, 90, 183.

Livshits, Igor, James MacGee, and Michele Tertilt, "Consumer Bankruptcy: A Fresh Start," American Economic Review, 2007, 97 (1), 402-418.

Lupica, Lois R, "The Consumer Bankruptcy Fee Study," American Bankruptcy Institute Law Review, 2012, 20, 17.

Mahoney, Neale, "Bankruptcy as Implicit Health Insurance," American Economic Review, 2015, 105 (2), 710-46.

_ and E Glen Weyl, "Imperfect Competition in Selection Markets," Review of Economics and Statistics, 2017, 99 (4), 637-651.

Mitman, Kurt, "Macroeconomic Effects of Bankruptcy and Foreclosure Policies," American Economic Review, 2016, 106 (8), 2219-55.

Morgan, Donald, Benjamin Iverson, and Matthew Botsch, "Subprime Foreclosures and the 2005 Bankruptcy Reform," Economic Policy Review, 2012, (March), 47-57.

Nakajima, Makoto, "Assessing Bankruptcy Reform in a Model with Temptation and Equilibrium Default," Journal of Public Economics, 2017, 145, 42-64.

Nelson, Scott, "Private Information and Price Regulation in the US Credit Card Market," Working Paper, 2018.

Parra, Carlos, "How Does Consumer Bankruptcy Protection Impact Household Outcomes?," Working Paper, 2018.

Posner, Richard, "The Bankruptcy Reform Act," Becker-Posner Blog, 2005. https://perma.cc/ XQ2G-5NS7. 
Ru, Hong and Antoinette Schoar, "Do Credit Card Companies Screen for Behavioral Biases?," National Bureau of Economic Research Working Paper \#22360, 2016.

Schuh, Scott D and Joanna Stavins, "The 2013 Survey of Consumer Payment Choice: Summary Results," Federal Reserve Bank of Boston Research Data Reports, 2015, (15-4).

Severino, Felipe and Meta Brown, "Personal Bankruptcy Protection and Household Debt," Working Paper, 2017.

Stango, Victor, "Competition and Pricing in the Credit Card Market," Review of Economics and Statistics, 2000, 82 (3), 499-508.

- and Jonathan Zinman, "What do Consumers Really Pay on Their Checking and Credit Card Accounts? Explicit, Implicit, and Avoidable Costs," American Economic Review, 2009, 99 (2), $424-29$.

_ and _, "Borrowing High versus Borrowing Higher: Price Dispersion and Shopping Behavior in the US Credit Card Market," The Review of Financial Studies, 2015, 29 (4), 979-1006.

Stavins, Joanna, "Can Demand Elasticities Explain Sticky Credit Card Rates?," New England Economic Review, 1996, pp. 43-55.

Tabb, Charles J, "Lessons from the Globalization of Consumer Bankruptcy," Law ES Social Inquiry, 2005, 30 (4), 763-782.

Wang, Hung-Jen and Michelle J White, "An Optimal Personal Bankruptcy Procedure and Proposed Reforms," The Journal of Legal Studies, 2000, 29 (1), 255-286.

Warren, Elizabeth, "The Phantom \$400," Journal of Bankruptcy Law and Practice, 2004, 13 (2).

_ , "Hearing before the Committee on the Judiciary," One Hundred Ninth Congress February 2005.

- and Amelia Warren Tyagi, "What's Hurting the Middle Class," Boston Review, September 2005 .

White, Michelle J, "Why Don't More Households File for Bankruptcy?," Journal of Law, Economics, \& Organization, 1998, pp. 205-231.

_ , "Bankruptcy Reform and Credit Cards," Journal of Economic Perspectives, 2007, 21 (4), 175200.

Woodward, Susan E and Robert E Hall, "Diagnosing Consumer Confusion and Sub-Optimal Shopping Effort: Theory and Mortgage-Market Evidence," American Economic Review, 2012, $102(7), 3249-76$.

Zame, William R, "Efficiency and the Role of Default When Security Markets are Incomplete," American Economic Review, 1993, pp. 1142-1164. 